Article

\title{
Towards Optimal Sustainable Energy Systems in Nordic Municipalities
}

\author{
Robert Fischer *(D), Erik Elfgren and Andrea Toffolo \\ Energy Engineering, Luleå University of Technology, SE-97187 Lulea, Sweden; erik.elfgren@ltu.se (E.E.) \\ andrea.toffolo@ltu.se (A.T.) \\ * Correspondence: robert.fischer@ltu.se; Tel.: +46-920-49-1454
}

Received: 27 November 2019; Accepted: 30 December 2019; Published: 7 January 2020

check for updates

\begin{abstract}
Municipal energy systems in the northern regions of Finland, Norway, and Sweden face multiple challenges: large-scale industries, cold climate, and a high share of electric heating characterize energy consumption and cause significant peak electricity demand. Local authorities are committed in contributing to national goals on $\mathrm{CO}_{2}$ emission reductions by improving energy efficiency and investing in local renewable electricity generation, while considering their own objectives for economic development, increased energy self-sufficiency, and affordable energy costs. This paper formulates a multi-objective optimization problem about these goals that is solved by interfacing the energy systems simulation tool EnergyPLAN with a multi-objective evolutionary algorithm implemented in Matlab. A sensitivity analysis on some key economic parameters is also performed. In this way, optimal alternatives are identified for the integrated electricity and heating sectors and valuable insights are offered to decision-makers in local authorities. Piteå (Norrbotten, Sweden) is used as a case study that is representative of Nordic municipalities, and results show that $\mathrm{CO}_{2}$ emissions can be reduced by $60 \%$ without a considerable increase in total costs and that peak electricity import can be reduced by a maximum of $38 \%$.
\end{abstract}

Keywords: municipal energy system; multi-objective optimization; renewable energy sources; EnergyPLAN

\section{Introduction}

The UNFCCC Paris Agreement aims at strengthening global responses to limit the increase of global average temperature to $1.5^{\circ} \mathrm{C}$ above pre-industrial levels. In the EU climate and energy framework the targets set by 2030 on greenhouse gas (GHG) emission reduction, renewable energy share, and energy efficiency improvement are 40\% (from 1990 levels), 32\%, and 32.5\%, respectively [1]. Sweden's binding target set by 2030 on GHG emission reduction was decided to be $40 \%$ from 2005 levels [2]. Global energy-related $\mathrm{CO}_{2}$ emissions continue to increase and have risen by $1.7 \%$ to $33.1 \mathrm{GtCO}_{2}$ in 2018 [3]. Sweden's territorial $\mathrm{CO}_{2}$ emissions from electricity generation and heating have dropped from a 2005 level of $9.3 \mathrm{MtCO}_{2}$ and reached $5.38 \mathrm{MtCO}_{2}$ in 2017 [4].

The project Arctic Energy, funded through the EU-program "Interreg Nord," was implemented by partner institutions from Finland, Sweden, and Norway between 2016 and 2018, and it provided energy systems analyses and simulations of future scenarios in order to support decision-makers of Nordic municipalities in their efforts to achieve GHG emissions targets and increase energy self-sufficiency, while ensuring secure and affordable energy supply [5]. This work continues the studies performed during the Arctic Energy project and investigates optimal alternatives for sustainable energy systems in Nordic municipalities with a focus on electricity and heating sectors.

Studies on Nordic municipal energy systems generally cover the heating sector, typically presenting the optimization of district heating (DH) systems. They include combined heat and power solutions, 
integration with industrial excess heat supply, solar heating, thermal energy storage, and investigations into next or 4th generation DH [6-9]. Further studies look into the potential of balancing intermittent renewable power production with power-to-heat solutions [10-13] and into the optimization of demand response measures [14]. Other research addresses various system aspects of heating demand and supply for buildings not served by DH. They include investigations into energy efficiency and renovation measures, demand management and user behavior, low or near-zero energy buildings, environmental impacts of biomass heating, and conversion of heating technologies [15-18].

In the recent past, electric heating shares have been between 70 and $80 \%$ in Norway [19], 32\% in Finland [20], and 26\% in Sweden [21]. Electric heating demand contributes to high peak electricity demands in the Nordic electricity sector, as illustrated by the Swedish case: minimum electricity consumption in Sweden was 8.6 GW on 16th July 2017, and maximum was $26.6 \mathrm{GW}$ on 5th January 2017 [22]. Sweden's responsible authority for the power transmission system (Svenska Kraftnät) expects capacity bottlenecks in the electricity supply of Swedish cities in the near future [23,24]. A typical medium size municipality in Sweden could reduce the annual electricity consumption by $10 \%$, and the peak electricity demand by $20 \%$, by converting from electric to non-electric heating [25].

Approaches to optimize energy systems have become more diverse and the number of studies into optimal solutions to support local decision-making processes has been increasing. Single-objective optimization methods typically focus on minimizing costs and provide the single best solution for one scenario, whereas multi-objective evolutionary algorithms generate a large number of optimal trade-off alternatives for conflicting objectives, including minimizing costs and reducing GHG emissions, maximizing intermittent renewable capacities, and minimizing curtailing and system losses. Optimal alternatives can then be subjected to multi-criteria decision-making methods in order to analyze a number of attributes [26-28]. Multi-Agent systems have also been proposed to model behavior and interactions between agents, which are key elements to generate robust, scalable, and context-aware energy optimization solutions [29]. Modelling tools for community scale energy systems and energy systems with large shares of variable renewables have been reviewed in [30-33].

EnergyPLAN is an advanced simulation tool, developed by Aalborg University [34], which allows the integration of the major sectors of any energy system (electricity, heat, transport, and industry) and supports the modelling of a stepwise transition to a sustainable energy system. EnergyPLAN has been applied in many instances at national, regional, and city level as well as on off-grid systems on islands [35-41]. Researchers have interfaced EnergyPLAN with optimization methods to find optimal solutions for multi-objective optimization problems. Bjelic et al. [42] analyzed the impact of the EU 2030 framework on the costs of the national energy system of Serbia. The approach of Mahbub et al. [43] provided an additional set of optimal solutions for the case of Aalborg municipality. Prina et al. [44] devoted particular attention to the analysis of energy efficiency in buildings. Thellufsen et al. [45] investigated a DH scenario in the Irish energy system and utilized the hourly simulation capability of EnergyPLAN in combination with the Irish energy system model, which is implemented in TIMES (The Integrated MARKAL-EFOM System).

The aims of this paper are to identify optimal alternatives for the integration of increased shares of local renewable electricity generation with a mix of heating technologies in the heating sector not connected to $\mathrm{DH}$ and to study the resulting interaction between electricity and heating sectors. The research investigates the multiple requirements of a Nordic municipality for a sustainable energy supply, which include the reduction of $\mathrm{CO}_{2}$ emissions, the increase of energy self-sufficiency through investments in local renewable electricity generation, the reduction of peak electricity demand caused by electric heating and, of course, the minimization of total annual energy system costs. The study further evaluates the effect of uncertain exogenous variables, such as electricity price, discount rates, and biomass price by performing a sensitivity analysis on these parameters.

This research interfaces EnergyPLAN with a multi-objective evolutionary algorithm (MOEA) implemented in Matlab [46], which has been successfully applied in a number of real-engineering problems, most recently on the optimization of a DH network expansion [47]. The energy system 
of Piteå municipality (Norrbotten, Sweden) is used as a representative case study for municipalities located in the northernmost regions of the Nordic countries.

The paper is structured as follows. Section 2 describes the methodology applied, the simulation and optimization tools and the key parameters of the municipal energy system model. Section 3 outlines the case study of Piteå, and Section 4 presents and discusses the main features of the optimal alternatives for the integrated electricity and heating sectors. Finally, Section 5 provides conclusive remarks and suggestions for further research.

\section{Methodology}

The deterministic simulation tool EnergyPLAN is used in this paper to model the electricity and heating sectors of the energy system of a Nordic municipality. EnergyPLAN executes a techno-economic analysis simulating the interactions between the modeled sectors on an hourly basis for a period of one year in very short processing times [37,48]. For a detailed description of EnergyPLAN, the reader is referred to the documentation available at [34].

This section defines the multi-objective optimization problem (MOOP) and describes the applied MOEA and the interface that has been implemented to exchange information with EnergyPLAN. Moreover, the values for key parameters of the energy model are discussed, such as electricity price, biomass price, discount rate, technology costs, and grid emission factors.

\subsection{The Multi-Objective Optimization Problem for a Generic Municipal Energy System}

\subsubsection{Objective Functions}

The objective functions to be minimized are the total annual system costs $C_{t o t}$ and the system $\mathrm{CO}_{2}$ emissions $E m_{s y s}$ of the electricity and heating sectors of a municipal energy system.

The total annual system $\operatorname{costs} C_{\text {tot }}$ calculated by EnergyPLAN are the sum of:

- The annualized capital cost $C_{a n n}$ of each component in the modelled energy system, which considers capital cost, expected lifetime, discount rate $d r$ and fixed operation and maintenance $(\mathrm{O} \& \mathrm{M})$ costs.

- Variable O\&M costs.

- Fuel costs, which depend on biomass price $p_{\text {bio }}$.

- Costs/revenues from the import/export of electricity from/to the grid, both calculated with the spot price $p_{e l}$.

- System $\mathrm{CO}_{2}$ emissions $E m_{\text {sys }}$ calculated by EnergyPLAN are the sum of:

- $\mathrm{CO}_{2}$ emissions due to the electricity imported from the national grid, $E m_{i m p}$, considering a grid emission factor $E F_{\text {grid }}$.

- $\mathrm{CO}_{2}$ emissions due to fossil fuel use within the boundaries of the municipal energy system.

\subsubsection{Decision Variables}

The decision variables of the MOOP deal with the way in which the demands of the electricity and heating sectors of the municipal energy system are covered.

The decision variables in the electricity sector are the installed capacities (in MW) for electricity generation technologies, such as hydropower, biomass-fired power, solar power, wind power. Lower bounds for the considered ranges of these variables can be set to zero or to existing installed capacities, whereas upper bounds can be set to limits depending, e.g., on the available areas found in municipal master plans for local renewable electricity generation technologies. Within the considered ranges, the values of the installed capacities are discretized according to the typical capacity of single electricity generation devices, e.g., a single wind turbine.

The decision variables in the heating sector are the amounts of heat (in GWh) supplied during a year by heating technologies both in district and individual heating systems, such as fossil fuel boilers, 
biomass boilers, electric boilers, heat pumps. The lower bound for the ranges of these variables is zero, and the upper bound is the annual heating demand that has to be covered by these technologies.

\subsubsection{Constraints}

Satisfying electricity and heating demand at any given time are the typical constraints in energy system modelling. EnergyPLAN calculates electric energy balances as a result of given demands, component behaviors, and selected regulation strategies. It imports or exports electricity from the grid utilizing the defined transmission line and provides warnings when certain limits are exceeded. Peak electricity import $P_{\text {el,maximp }}$ is an important output of the calculations, because Nordic countries have a high share of electric heating that results in extreme peak demand during the heating period. $P_{\text {el,maximp }}$ is most relevant for municipalities in which transmission line capacities can become a bottleneck. The same bottleneck could limit the installation of new local electricity generation capacity, or could lead to curtailing, because of the increase of electricity export to the national grid. Peak electricity export $P_{\text {el,maxexp }}$ is therefore another output to be monitored.

Heating demand is balanced at any time, as the sum of the values of the decision variables related to the heating supply must be equal to the annual heating demand.

\subsection{The Optimization Algorithm and the Interface with EnergyPLAN}

The multi-objective evolutionary optimization algorithm (MOEA) described in [46] was adapted to search for the optimal trade-offs of the defined MOOP. The main feature of this MOEA is a diversity-preserving mechanism that treats diversity as a meta-objective in the evaluation phase. In order to reduce the computational effort, a consolidation ratio [49] is adopted as the criterion to terminate the search process. The numerical results, including those that this paper presents, prove that the solutions effectively converge toward the Pareto optimal front and that they are well distributed.

Figure 1 gives an overview about the interface between the MOEA and EnergyPLAN modelling and simulation procedure and about the wrapper software that has been developed for the exchange of information.

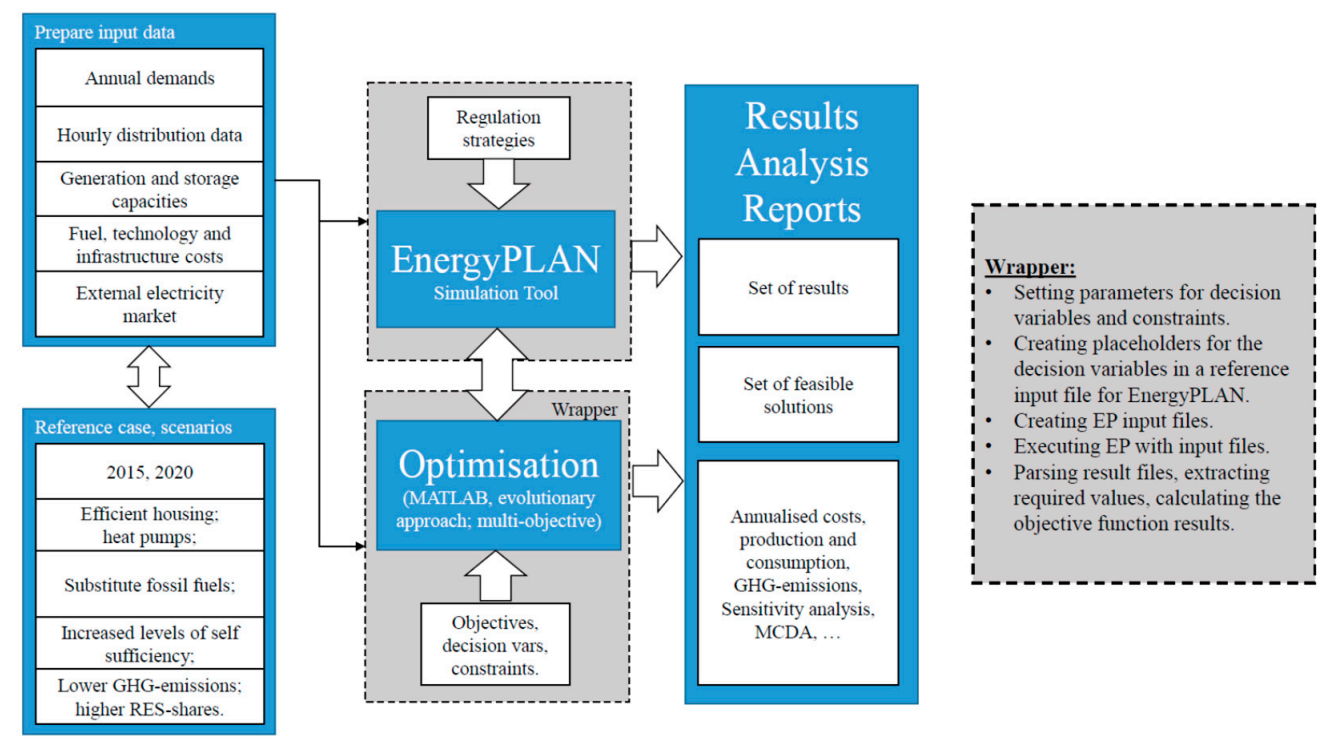

Figure 1. Schematic diagram of the interface between EnergyPLAN (simulation) and the multi-objective evolutionary algorithm (MOEA) (multi-objective optimization).

\subsection{Model Parameters and Uncertainties}

Energy system analysis has to deal with multiple uncertainties related to technical, environmental, and economic parameters. In this study, sources of uncertainty for local renewable energy production 
include site-specific climate data and the capacity factors of the different technologies. Different $\mathrm{CO}_{2}$ emission accounting methods can lead to significant differences in emission factors. The estimation of costs is directly affected by the economic parameters, such as technology costs, electricity and fuel prices, and discount rates.

\subsubsection{Electricity Price $p_{e l}$}

Calculated costs for imported electricity and revenues for exported electricity are included in the economic objective function of the MOOP. These are based on the hourly electricity spot price $p_{e l}$ for the Nordic electricity system as available from the NordPool power market [22]. The selection of $p_{e l}$ value is based on the historical price trend of Nordic power market, where the average annual electricity spot price moves between a long term low of 21 EUR/MWh in 2015 and 50 EUR/MWh by the end of 2018. The considered values for the annual average $p_{e l}$ in the sensitivity analysis are then 20,40 , and $60 \mathrm{EUR} / \mathrm{MWh}$.

\subsubsection{Biomass Price $p_{b i o}$}

The price of biomass (pellets) $p_{b i o}$ affects the costs associated with the heating sector that is not supplied by DH. Swedish pellet prices from 2010 to 2018 show a range of the annual average $p_{b i o}$ between 34.39 EUR/MWh in 2017 and 38.03 EUR/MWh in 2011 [50] (including delivery for household supply). In EnergyPLAN cost database for $2020 p_{b i o}$ for household supply consists of two parts: biomass price and delivery costs. Delivery costs are kept constant in the sensitivity analysis, and the considered values for $p_{b i o}$ are $26.25,35.0$, and $43.75 \mathrm{EUR} / \mathrm{MWh}$. This price setting reflects a development of the future $p_{b i o}$ within $\pm 25 \%$ from the 2018 annual average of $35.0 \mathrm{EUR} / \mathrm{MWh}$.

\subsubsection{Discount Rate $d r$}

Discounting in energy system analysis considers two perspectives: social $d r$, for evaluating costs and benefits from a societal perspective, and individual $d r$, for evaluating investment decisions [51]. Applied social $d r$ in energy studies ranges between $1 \%$ and $7 \%$ and the $d r$ for industrial investors ranges from $6 \%$ to $15 \%$ [51,52]. In the sensitivity analysis of this study the considered values for $d r$ are $3 \%, 9 \%$, and $15 \%$.

\subsubsection{Technology Costs}

Technology cost parameters are available from the EnergyPLAN package [34]. References of EnergyPLAN cost database include the catalogues of energy technology data published by the Danish Energy Agency and Energinet, JRC Technical Reports and the ETRI projections for 2010-2050 [53-55]. It is assumed in this study that technology costs are sufficiently reliable, especially with the consideration that all the technologies associated with the decision variables are mature.

\subsubsection{Weather Conditions}

Annual heating demand and annual electricity generation from windpower, hydropower, and solar PV can vary significantly in different years because of the weather conditions. In this work the weather data set used refers to a specific period of only one year (2015), although the study of selected years with extreme weather data would address uncertainties arising from unpredictable weather conditions.

\subsubsection{Grid Emission Factor $E F_{\text {grid }}$}

The European Joint Research Center (JRC) published National and European Emission Factors for Electricity consumption (NEEFE) [56,57]. JRC recommends that NEEFE are applied in the emission inventories of the municipalities that signed the EU Covenant of Mayors for Climate and Energy (CoM), a network of local governments committed to implementing EU climate and energy objectives. 
Most Swedish signatory municipalities historically created their emission inventories applying the $E F_{\text {grid }}$ of the Nordic electricity mix, which considers import dependencies of the Nordic electricity market 2015 [58]. Currently no Swedish institution regularly updates $E F_{\text {grid }}$ values for the Nordic electricity mix. Table 1 presents the different $E F_{\text {grid }}$ values for Sweden in 2015.

Table 1. Grid emissions factors $E F_{\text {grid }}$ in Sweden 2015.

\begin{tabular}{ccc}
\hline Sweden, $\boldsymbol{E} \boldsymbol{F}_{\text {grid }}$ 2015 & Value & Unit \\
\hline NEEFE (IPCC standard) & 0.0150 & $\mathrm{tCO}_{2 /} \mathrm{MWh}$ \\
NEEFE (IPCC standard+) & 0.0160 & $\mathrm{tCO}_{2 \mathrm{eq}} / \mathrm{MWh}$ \\
NEEFE (LCA) & 0.0380 & $\mathrm{tCO}_{2 \mathrm{eq}} / \mathrm{MWh}$ \\
Nordic electricity mix 2015 & 0.0665 & $\mathrm{tCO}_{2 \mathrm{eq}} / \mathrm{MWh}$ \\
Nordic electricity mix 2010 & 0.1000 & $\mathrm{tCO}_{2 \mathrm{eq}} / \mathrm{MWh}$ \\
\hline
\end{tabular}

Different $\mathrm{CO}_{2}$ emission accounting methods lead to significant differences in $E F_{\text {grid }}$ values. The energy system model in this paper neglects the $\mathrm{CO}_{2}$ emissions from local renewable energy production, as for $\mathrm{CoM}$ signatory municipalities all local renewable energy generation can be considered as $\mathrm{CO}_{2}$ free [56], so that $\mathrm{CO}_{2}$ emissions are merely a consequence of imported electricity $E m_{\text {imp }}$ according to the selected value of $E F_{\text {grid }}$.

\section{The Piteå Case Study in EnergyPLAN}

A case study for the Pitea municipal energy system was implemented by the authors in EnergyPLAN as part of the Arctic Energy project between 2016 and 2018 [5]. Piteå municipality, located in Norrbotten county of Sweden, participated in the project and can be considered as a representative municipality in the Nordic context. Pitea became a signatory to the CoM in 2009, submitted the Sustainable Energy Action Plan (SEAP) to CoM in 2010 [59], and has renewed its commitment to CoM in 2017 [60]. In the 2010 SEAP Piteå sets the following targets for the municipality and its energy sector to be achieved by 2020 :

- $\quad$ Reduce GHG emissions of the entire municipality by $50 \%$ (base year 1998).

- Convert all fossil fuel fired boilers for heating and industrial processes.

- Reduce net energy demand by $20 \%$ for apartment and commercial buildings and $10 \%$ for single-family homes (base year 2008).

- Supply electricity and heating demand with $100 \%$ renewable sources.

- Become a net exporter of renewable electricity.

The SEAP also details a number of measures to be implemented and a progress report presents achieved results by 2013 [61].

Piteå had 41,548 inhabitants by 2015. 145 MW of wind power, $40.9 \mathrm{MW}$ of hydropower, $256 \mathrm{kWp}$ of PV were installed within the municipal boundaries. Industrial biomass fueled combined heat and power (CHP) plants, with an aggregated power production capacity of $78 \mathrm{MW}$, supplied about $53 \%$ of the own electricity demand of these industries. The total final electricity consumption of Pitea municipality was $1453 \mathrm{GWh}$ in 2015, of which 1117 GWh were supplied from local generation and the reminder was imported from the national grid. DH supplied $269 \mathrm{GWh}$ of heat in urban areas, mainly utilizing industrial excess heat. Heat consumption in buildings not connected to DH was $238 \mathrm{GWh}$, of which $166 \mathrm{GWh}$ were provided by electric heating, including heat pumps, and $70 \mathrm{GWh}$ from biomass boilers. More key figures about Piteå are presented in Table 2 with references to the sources. 
Table 2. Piteå municipality, key figures 2015.

\begin{tabular}{|c|c|c|c|}
\hline Population, Land Area & Value & Unit & References * \\
\hline Population & 41,548 & [1] & [62]-BE0101 \\
\hline Population expected by 2030 & 43,069 & [1] & [63] \\
\hline Land area & 3086 & {$\left[\mathrm{~km}^{2}\right]$} & [62]-MI0802AA \\
\hline $\begin{array}{c}\text { Main Cities (Population >1000); } \\
\text { Housing }\end{array}$ & Value & Unit & References * \\
\hline Piteå (administrative seat) & 23,067 & [1] & [62]-BE0101 \\
\hline Bergsviken & 2251 & [1] & [62]-BE0101 \\
\hline Rosvik & 1848 & [1] & [62]-BE0101 \\
\hline Norrfjärden & 1562 & [1] & [62]-BE0101 \\
\hline Roknäs & 1259 & [1] & [62]-BE0101 \\
\hline Hortlax & 1128 & [1] & [62]-BE0101 \\
\hline Housing-number of dwellings & 19,273 & [1] & [62]-BO0104AE, BO0104AG \\
\hline In residential buildings & 11,509 & [1] & \\
\hline In apartment buildings & 7384 & [1] & \\
\hline In other buildings & 380 & [1] & \\
\hline Energy Consumption/Production & Value & Unit & References * \\
\hline Total final energy consumption & 5901 & [GWh] & [62]-EN0203AE \\
\hline Total final electricity consumption & 1453 & [GWh] & [62]-EN0203AE, [64] \\
\hline Municipal electricity production & 1117 & [GWh] & [62]-EN0203AD, [65] \\
\hline Industrial $\mathrm{CHP}$ & 499 & [GWh] & {$[66]$} \\
\hline Hydropower & 221 & [GWh] & [62]-EN0203AD, [67] \\
\hline Windpower & 397 & [GWh] & [62]-EN0203AD \\
\hline Total heat production by $\mathrm{DH}$ & 269 & [GWh] & [62]-EN0203AC, [64] \\
\hline Industrial waste heat & 257 & [GWh] & {$[66]$} \\
\hline Heating centers (boilers) & 11 & [GWh] & {$[65]$} \\
\hline Total heat energy consumption (no DH) & 238 & [GWh] & [62]-EN0203AE, $[65,68,69]$ \\
\hline Electricity (direct) & 146 & [GWh] & [62]-EN0203AE, $[65,68,69]$ \\
\hline Electricity (heat pump) & 20 & [GWh] & [62]-EN0203AE, [65,68,69] \\
\hline Biomass & 70 & [GWh] & [62]-EN0203AE, $[65,68,69]$ \\
\hline Oil & 2 & [GWh] & [62]-EN0203AE, $[65,68,69]$ \\
\hline
\end{tabular}

${ }^{*}$ references to SCB [62] include the internal reference code to the specific data.

\subsection{Case Study Decision Variables}

The choice of the decision variables in this case study is strictly related to the peculiar features of the municipal energy system in Piteå.

In the electricity sector, the decision variables are the installed capacities (in MW) for three local renewable electricity generation technologies: utility scale solar PV systems (PV), onshore wind turbines (WindON), and offshore wind turbines (WindOFF). A possible expansion of hydropower capacity is not considered because of environmental legislation [70]. Biomass-fired CHP plants are not considered because the heating demand satisfied with $\mathrm{DH}$ is already covered with waste heat from industries, and the DH network already connects the most densely populated areas in the municipality. In this study the capacity of the transmission line is set to unlimited and resulting values for electricity import and export are discussed.

In the heating sector, it is assumed that $\mathrm{DH}$ will continue to operate as it presently does. Accordingly, the decision variables are related to individual heating systems, and they are the amounts of heat (in GWh) supplied during a year by biomass boilers (BioB), heat pumps (HP) and electric heating (ElB).

Table 3 shows the levelized costs of electricity LCOE in EUR/MWh and the annualized capital cost $C_{a n n}$ in EUR/MW for the considered renewable electricity generation technologies, and $C_{a n n}$ in EUR/unit for the considered heating technologies. The EnergyPLAN cost database provided technology cost 
parameters to calculate these values, which will be important for later discussions. A 50/50\% mix of air-air heat pumps and ground source heat pump types is considered for HP according to sale statistics [71]. LCOE takes into account the technology costs for 2020 and considers average capacity factors for the Nordic location. It is important to note that $C_{a n n}$ for renewable electricity generation is lowest for PV and highest for WindOFF, while LCOE is lowest for WindON and highest for PV due to the different capacity factors.

Table 3. $L C O E, C_{a n n}$ for PV, WindON, and WindOFF; $C_{a n n}$ for ElB, BioB, and HP (calculations based on 2020 technology cost parameters as provided by the EnergyPLAN cost database).

\begin{tabular}{|c|c|c|c|c|}
\hline \multirow[b]{2}{*}{ Renewable Energy Technology } & \multirow[b]{2}{*}{ Capacity Factor } & \multicolumn{3}{|c|}{ LCOE [EUR/MWh] } \\
\hline & & $d r=3 \%$ & $d r=9 \%$ & $d r=15 \%$ \\
\hline Solar PV (PV) & $12 \%$ & 47 & 85 & 130 \\
\hline Wind onshore (WindON) & $30 \%$ & 33 & 50 & 70 \\
\hline \multirow[t]{2}{*}{ Wind offshore (WindOFF) } & $40 \%$ & 43 & 68 & 99 \\
\hline & & \multicolumn{3}{|c|}{$C_{a n n}[\mathrm{EUR} / \mathrm{kW}]$} \\
\hline Renewable Energy Technology & & $d r=3 \%$ & $d r=9 \%$ & $d r=15 \%$ \\
\hline Solar PV (PV) & & 50 & 89 & 136 \\
\hline Wind onshore (WindON) & & 86 & 130 & 184 \\
\hline \multirow[t]{2}{*}{ Wind offshore (WindOFF) } & & 149 & 239 & 347 \\
\hline & & \multicolumn{3}{|c|}{$C_{a n n}[\mathrm{EUR} / \mathrm{unit}]$} \\
\hline Heating Technology & & $d r=3 \%$ & $d r=9 \%$ & $d r=15 \%$ \\
\hline Electric heating (ElB) & & 177 & 316 & 481 \\
\hline Biomass boiler (BioB) & & 933 & 1212 & 1543 \\
\hline Air-air heat pump (AAHP) & & 185 & 239 & 300 \\
\hline Ground-source heat pump (GSHP) & & 1069 & 1619 & 2272 \\
\hline Heat pump mix: GS-AA-HP (HP) & & 711 & 1001 & 1339 \\
\hline
\end{tabular}

\subsection{Selected Scenarios Simulated with EnergyPLAN}

The model of the Piteå municipal energy system was built in EnergyPLAN and a number of scenarios were simulated for reference before coupling the model to the optimization algorithm (Figure 2) [5].

The "Base2015" scenario was simulated to analyze the situation in the year 2015. With technology costs for 2015, an average $p_{e l}$ for the Nordic electricity system of 40 EUR/MWh and a $d r$ of $9 \%, C_{t o t}$ resulted equal to 81.9 MEUR (Figure 2). The calculated value for $E m_{\text {sys }}$ was $37.4 \mathrm{ktCO}_{2}$, neglecting the $\mathrm{CO}_{2}$ emission from local renewable energy generation as recommended by JRC to CoM signatory municipalities to consider as $\mathrm{CO}_{2}$ emissions free [56]. This is a consequence of a $374 \mathrm{GWh}$ grid electricity import with a grid emission factor for the Nordic electricity mix of $0.1 \mathrm{tCO}_{2 \mathrm{eq}} / \mathrm{MWh}$, the same applied in the emission inventory for Piteå as presented in the Piteå SEAP [59].

Technology costs for 2020 (see Section 2 and Table 3) and an average $p_{e l}$ for the Nordic electricity system of $40 \mathrm{EUR} / \mathrm{MWh}$ were used as standard parameters in all scenarios related to year 2020. The "Demand2020" scenario simulated a variation of the demand in electricity and heating sectors with respect to the 2015 situation, because of the achievement of the following 2020 targets mentioned in Piteå SEAP: the conversion of fossil fuel heating into renewable heating, considering a mix of biomass and heat pump solutions, and the implementation of energy efficiency measures in the building sector. This resulted in a reduction of electricity import (358 MWh) and $E m_{\text {sys }}\left(35.8 \mathrm{tCO} \mathrm{CO}_{2 \mathrm{eq}} / \mathrm{MWh}, 5.8 \%\right.$ less than Base2015). The calculated $C_{\text {tot }}$ (with $d r=9 \%$ ) was 78.1 MEUR, 4.6\% less than in Base2015, but if 2020 technologies costs were applied to the 2015 situation (Base2015-costs2020 scenario) then the reduction in $C_{\text {tot }}$ would be $2.4 \%$ only (Figure 2). 
The "Balanced2020" scenarios were inspired by the net-export 2020 target in Pitea SEAP, because they simulate the condition in which there is a near-zero balance between electricity import and export considering a one year period. In each Balanced2020 scenario this condition was achieved by investing in additional capacities of a different mix of renewable electricity generation technologies (PV, WindON and WindOFF) starting from the Demand2020 situation. EnergyPLAN is able to deliver fast results for integrated energy system studies and the user can analyze different options in order to approach defined conditions for the modelled energy system. The options for the mix of technologies are chosen by the user on the basis of available domain knowledge. A condition such as a near-zero balance is relatively easy to achieve when only few technologies are included in the set of options, thanks to the EnergyPLAN feature that allows the user to perform a series of simulations in one run with up to 11 different values for a parameter (in this case the capacity of one renewable electricity generation technology).

Comparing the simulated Balanced2020 scenarios with Demand2020 (Figure 2), $C_{\text {tot }}(d r=9 \%$ ) increase between $2.2 \%$ and $12.9 \%$, while $\mathrm{CO}_{2}$ emissions are reduced to a minimum of $20.6 \mathrm{ktCO}_{2}$ $(-42.5 \%)$ in the Balanced2020-WindON-OFF-PV scenario (with $145 \mathrm{MW}$ WindON, $100 \mathrm{MW}$ PV and $60 \mathrm{MW}$ WindOFF additional capacities). Base2015 $P_{\text {el,maximp }}(168.3 \mathrm{MW})$ is reduced in the Demand 2020 scenario to $164.7 \mathrm{MW}(-2.1 \%)$, and further reduced to a minimum of $157.8 \mathrm{MW}$ in the Balanced2020-WindON-OFF scenario.

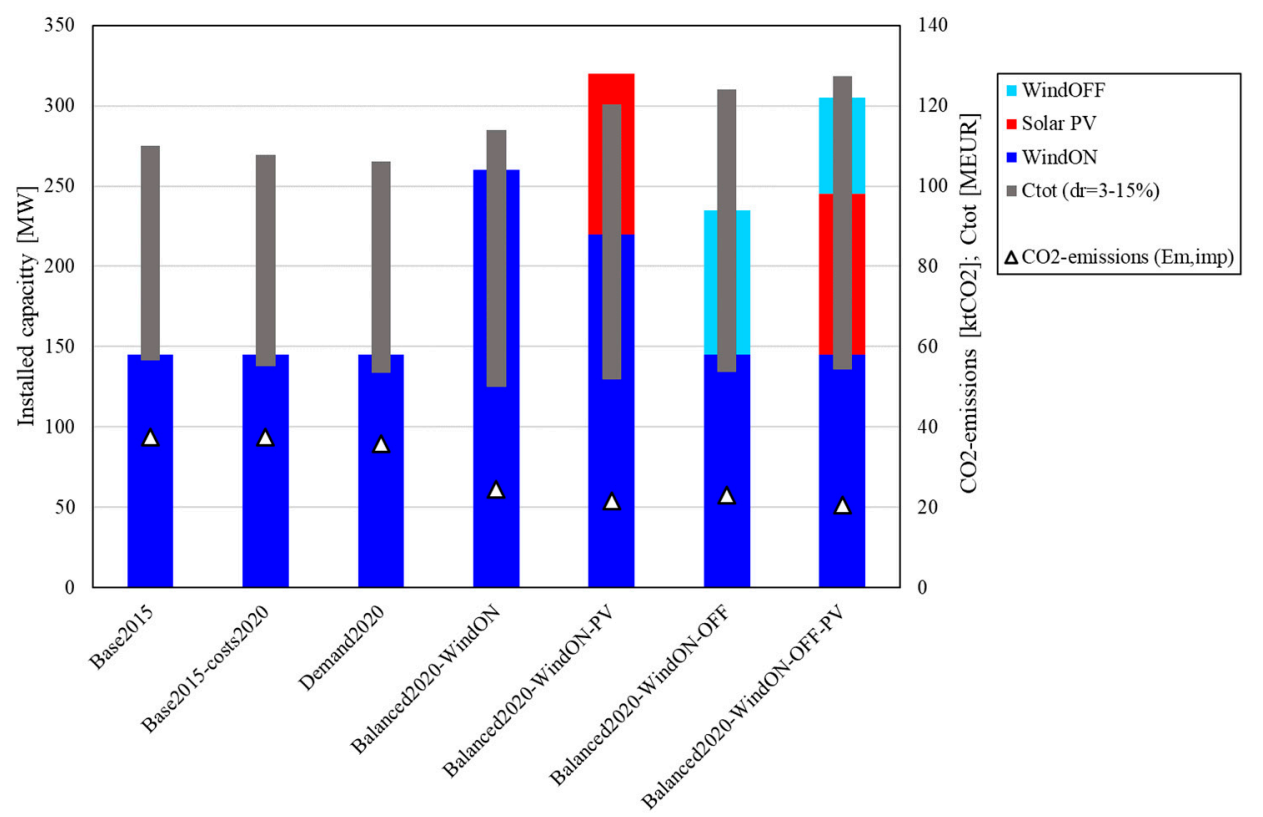

Figure 2. Selected reference scenarios simulated in EnergyPLAN for the Piteå municipal energy system; $p_{e l}=40 \mathrm{EUR} / \mathrm{MWh}, p_{\text {bio }}=35 \mathrm{EUR} / \mathrm{MWh}$.

Balanced2020 scenarios provide possible alternatives to achieve the near-zero balance condition as created by an EnergyPLAN user, without an indication whether the corresponding $\mathrm{CO}_{2}$ emission reductions are obtained with a minimum cost increase. On the contrary, the multi-objective optimization approach shall provide better knowledge of the alternatives that represent the optimal trade-offs between the two conflicting objectives of the MOOP.

\subsection{Setup of Parameters for the MOOP}

The starting point of the optimization runs is the energy system model of Piteå municipality with the parameters of Demand2020 scenario. It is worth noting that in this scenario the only $\mathrm{CO}_{2}$ emissions are those due to electricity import, since no fossil fuel is used either in the electricity or heating sector, and, therefore, $E m_{\text {sys }}$ is equal to $E m_{\text {imp }}$. 
Table 4 lists the chosen ranges and the discretization steps for the decision variables of the MOOP defined in this study. Maximum PV capacity (100 MW) was determined by limiting land use to about $0.1 \%$ of the available land area of Pitea municipality. The discretization step of $1 \mathrm{MW}$ reflects the utility scale for ground-mounted solar PV systems. The discretization steps for WindON and WindOFF were set according to the capacity of single wind turbines typically installed in such wind developments in recent years. Minimum WindON capacity of $145 \mathrm{MW}$ was the existing installed capacity in 2015, whereas the maximum was set to $505 \mathrm{MW}$ in order to allow for the installation of one hundred additional wind turbines of 3.6 MW each [72]. Maximum WindOFF capacity was set to $330 \mathrm{MW}$ considering the available area declared in the wind development plan of Pitea and in published project plans for this area [72,73]. Higher technical potentials exist anyway for all technologies. The decision variables for the heating sector (ElB, BioB, and HP) are continuous and the sum of the amounts of heat supplied by the three technologies has to satisfy the annual heating demand of the individual heating sector (i.e., the demand from buildings not connected to DH, 211.7 GWh according to the Demand2020 scenario).

Table 4. Decision variables for local renewable electricity generation and heating technologies.

\begin{tabular}{lccc}
\hline Renewable Electricity Generation Technology & PV [MW] & WindON [MW] & WindOFF [MW] \\
\hline Minimum & 0 & 145 & 0 \\
Discretization step & 1 & 3.6 & 6 \\
Maximum & 100 & 505 & 330 \\
\hline \multicolumn{1}{c}{ Heating Technology } & BioB [GWh] & HP [GWh] & ElB [GWh] \\
\hline Minimum & 0 & 0 & 0 \\
Discretization & & Continuous & 211.7 \\
Maximum = heating demand & 211.7 & 211.7 & 2 \\
\hline
\end{tabular}

\section{Results and Discussion}

Two different sets of optimization runs were performed considering the decision variables of (a) electricity sector only and (b) integrated electricity and heating sectors. Within each set, the optimization runs are repeated with different values of the economic parameters discussed in Section 2 to implement sensitivity analysis. Initial test runs confirmed sufficient diversity and convergence toward the Pareto front, considering that the termination criterion on the consolidation ratio is satisfied, as described in Section 2. The electricity sector only runs were then configured with 100 individuals and 300 generations, whereas integrated electricity and heating sectors runs were configured with 200 individuals and 500 generations.

The figures in the following subsections present the Pareto fronts plotting $C_{t o t}$ vs. $\mathrm{CO}_{2}$ emission reduction with respect to Demand2020 scenario, and the Pareto sets of optimal solutions plotting the optimal values of the decision variables vs. $\mathrm{CO}_{2}$ emissions reduction with respect to Demand2020 scenario. The effects of the optimal solutions on $P_{\text {el,maximp }}$ are also discussed.

\subsection{Electricity Sector Only}

Figure 3 presents the optimal results obtained about the case study considering the capacities of the three renewable electricity generation technologies (PV, WindON, and WindOFF) as the decision variables of the MOOP. These technologies differ widely in $C_{a n n}$, which is affected by $d r$ and LCOE (in the latter the capacity factor is also an important parameter, see Table 3). The different values of the economic parameters considered in the sensitivity analysis have a significant impact on the cost objective function of the MOOP. In fact, these parameters will affect the relative weights in $C_{\text {tot }}$ of investment costs and operational costs/revenues due to electricity import/export: for a constant $p_{e l}$, a higher $d r$ will increase $C_{a n n}$ and in turn $C_{t o t}$, whereas a higher $p_{e l}$ will dampen the growth of $C_{\text {tot }}$ as electricity export will generate larger revenues when installed generation capacities increase. 
This plays a fundamental role in determining which combinations of technologies are the optimal trade-offs among the conflicting objectives of the MOOP.

WindOFF has the highest $C_{a n n}$ of the three technologies and a LCOE between WindON and PV because of the highest capacity factor (40\%); on the other hand WindON, in spite of having a higher $C_{a n n}$ than PV, has a lower $L C O E$ thanks to the higher capacity factor $(30 \%$ vs. $12 \%$, see Table 3$)$. In the $3 \times 3$ diagrams in Figure $3 C_{\text {tot }}$ is dominated by the investment costs when a) $p_{e l}=20$ EUR/MWh, which is below all LCOEs with all $d r$; b) $p_{e l}=40$ EUR/MWh with $d r=9 \%$ and $15 \%$; c) $p_{e l}=60$ EUR/MWh with $d r=15 \%$. In these cases, WindOFF contributes to the optimal solutions only when both WindON and PV have already reached their considered maximum installed capacities, meaning that further $\mathrm{CO}_{2}$ emission reductions from that condition are only possible with investments in WindOFF, which are the least convenient for those values of the economic parameters.

As operational costs/profits start to counterbalance investment costs, the slope with which $C_{\text {tot }}$ increases as $\mathrm{CO}_{2}$ emissions are reduced decreases, up to the point in which the Pareto front does not contain solutions with small $\mathrm{CO}_{2}$ emission reduction. With $p_{e l}=40 \mathrm{EUR} / \mathrm{MWh}$ and $d r=3 \%$ all solutions feature WindON at the maximum capacity, starting from emission reductions of $58 \%$ at minimum $C_{\text {tot }}$ with zero capacity of WindOFF and PV. This means that is no longer economically convenient to look for solutions that achieve $\mathrm{CO}_{2}$ emissions reductions below $58 \%$ because of the large profits that can be achieved by exporting the electricity generated with WindON, which has to be exploited at the maximum considered capacity. From this condition, WindOFF provides better trade-offs than PV and increases its capacity up to the maximum, resulting in emission reductions of about $80 \%$. Only when all available wind capacities are fully utilized PV becomes part of the solution set, further reducing emissions by $85 \%$.

With more significant operational profits due to $p_{e l}=60 \mathrm{EUR} / \mathrm{MWh}$ (at $d r=9 \%$ ), emission reduction at minimum $C_{\text {tot }}$ is even slightly higher than $60 \%$ and, again, all optimal solutions feature WindON at its maximum capacity. As the optimal $C_{\text {tot }}$ increases from its minimum value both PV and WindOFF are convenient enough from the economic point of view to be featured in the solution set.

Finally, when the revenues from exported electricity totally prevail over investment costs $\left(p_{e l}=60\right.$ EUR/MWh and $d r=3 \%$ ), all LCOEs fall below $p_{e l}$ and the two objectives of the MOOP are no longer conflicting. In this case only one optimal solution exists, featuring maximum installed capacities for all three technologies. Please note that, as expected, all the Pareto optimal set of solutions obtained for different values of $p_{e l}$ and $d r$ end up in this same solution (which also corresponds to maximum $\mathrm{CO}_{2}$ emission reduction, $85 \%$ ), since this is due to the upper limit chosen for the ranges for the decision variables.

It is important to observe that, in spite of its low capacity factor (12\%) due to the Nordic location, $\mathrm{PV}$ is shown to be more economically convenient than WindOFF in six out of the nine considered combinations of the economic parameters.

Figure 4 shows the reductions achieved in peak electricity import $P_{\text {el,maximp }}$ with the optimal solutions obtained considering the three renewable electricity generation technologies (all diagrams correspond to those in the same position in Figure 3). In Piteå municipality $P_{\text {el,maximp }}$ can be reduced from $165 \mathrm{MW}$ (Demand2020 scenario) to $129 \mathrm{MW}(-21.8 \%$ or $36 \mathrm{MW})$ by installing maximum capacities for all the three technologies. A Svenska Kraftnät report on wind power integration estimates the minimum availability factor of wind power across Sweden at 6\% [74]. If this $6 \%$ were applied to the additional $690 \mathrm{MW}$ capacity of WindON and WindOFF installed in the Demand2020 scenario, the wind turbines would provide $41.4 \mathrm{MW}$ as a minimum, confirming the reliability of the simulation results from EnergyPLAN. 

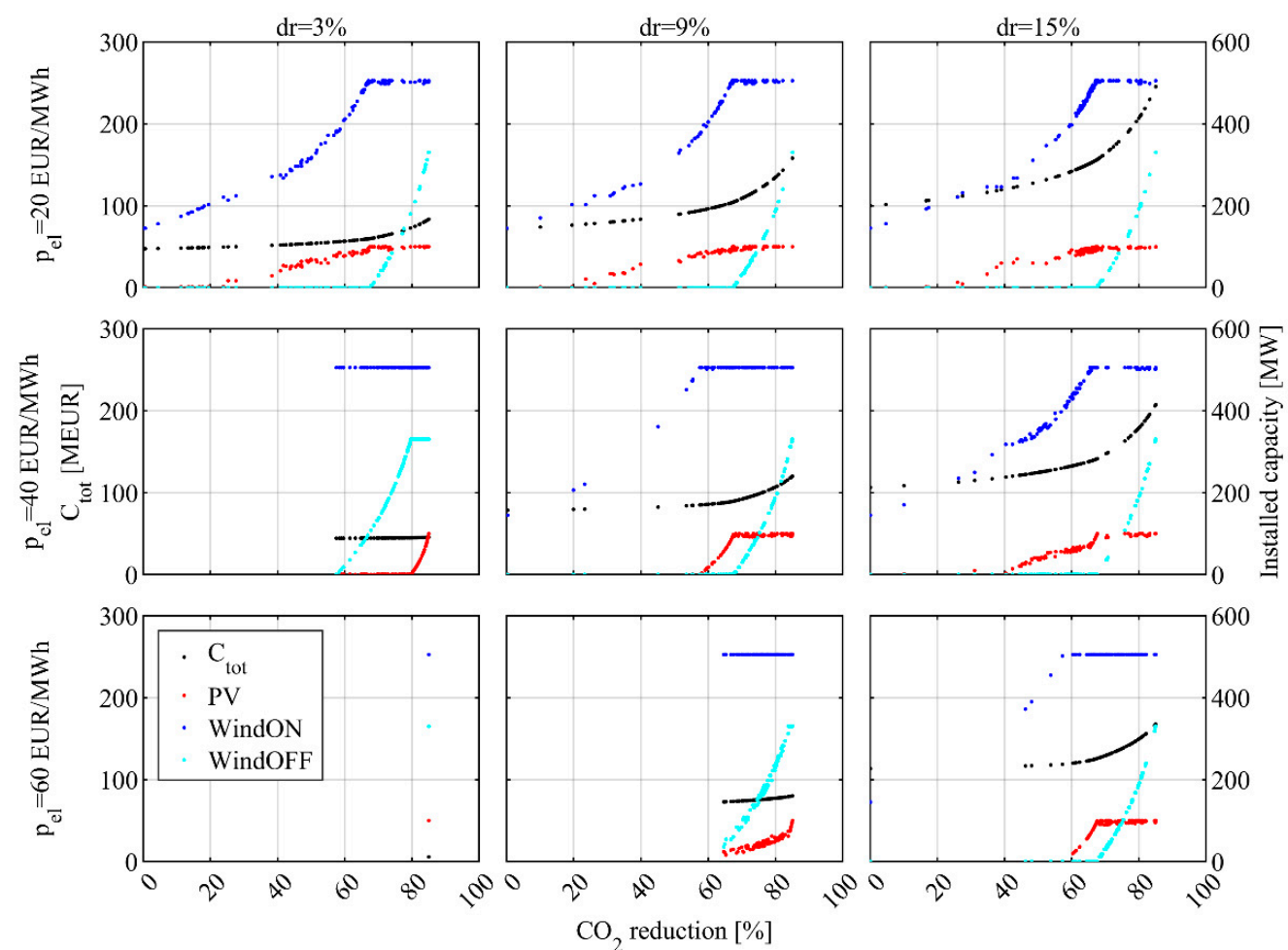

Figure 3. Electricity sector, optimal results with three decision variables (PV, WindON and WindOFF), sensitivity analysis for $p_{e l}$ and $d r$.
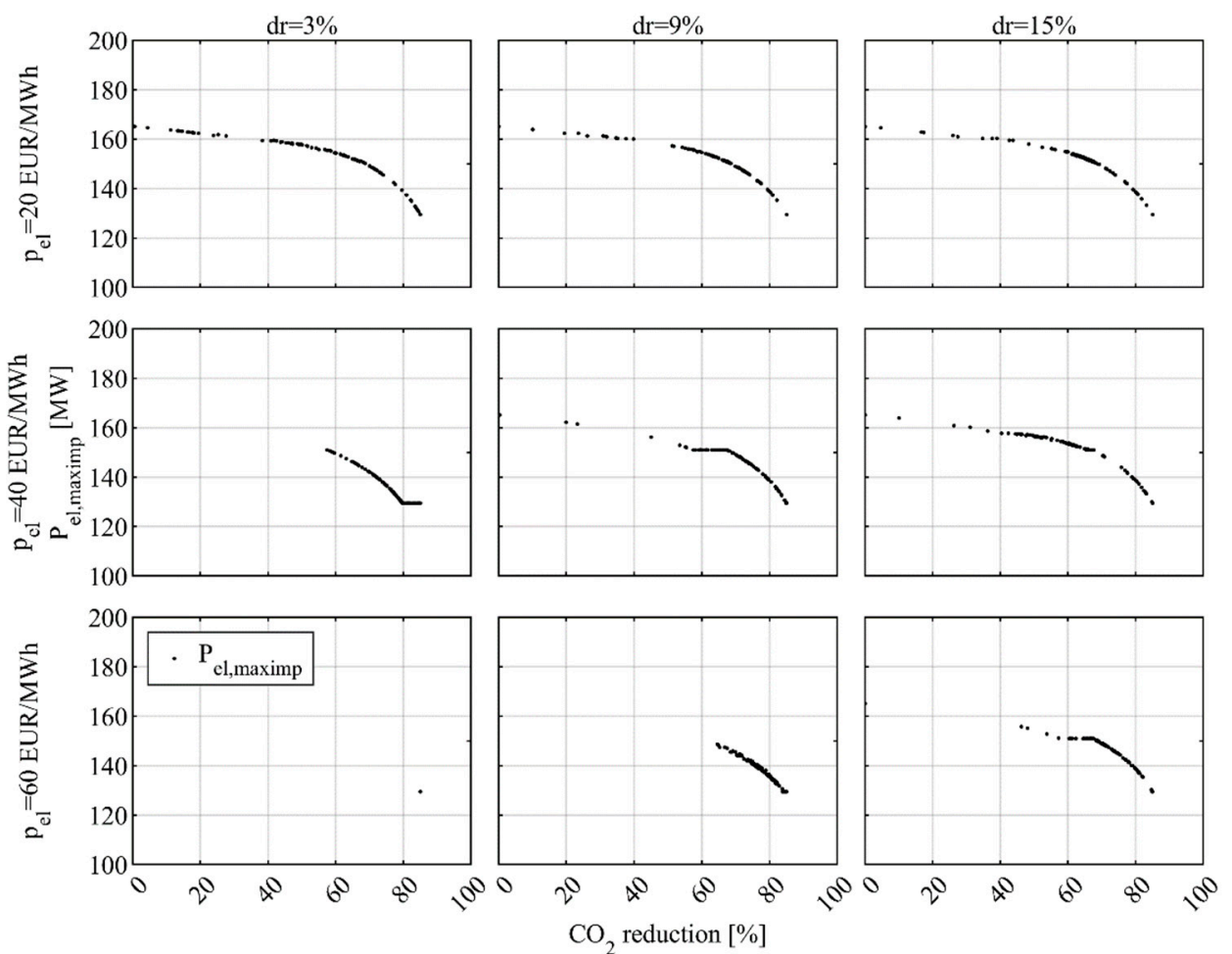

Figure 4. Electricity sector, $P_{\text {el,maximp }}$ with three decision variables (PV, WindON and WindOFF) sensitivity analysis for $p_{e l}$ and $d r$. 


\subsection{Integrated Electricity and Heating Sectors}

This subsection presents the results of the optimization runs in which all the six decision variables of the MOOP are considered (PV, WindON, WindOFF, ElB, HP, BioB). This means that the electricity and heating sectors are considered integrated and optimized together, enabling the analysis of potential interactions between these sectors. Figure 5 duplicates the number of diagrams in the $3 \times 3$ grid already used in Figure 3, since the optimal values of decision variables related to the electricity sector are shown separated from those related to the heating sector for sake of clarity. In Figure 5 a low $p_{e l}$ (20 EUR/MWh) is paired with high $p_{\text {bio }}(43.75 \mathrm{EUR} / \mathrm{MWh})$, in Figure $5 \mathrm{~b}$ the central values of $p_{e l}$ and $p_{b i o}$ are paired (40 EUR/MWh and 35 EUR/MWh, respectively), and in Figure $5 \mathrm{c}$ high $p_{e l}(60 \mathrm{EUR} / \mathrm{MWh})$ is paired with low $p_{b i o}(26.25 \mathrm{EUR} / \mathrm{MWh})$. These combinations of $p_{e l}$ and $p_{b i o}$ values are paired in turn with all the considered values for $d r$.

From the diagrams in Figure 5 it is apparent that the optimal decision variable values for the renewable electricity generation technologies follow in general the same trends as in Figure 3, but with some significant differences related to the interaction with the heating sector. Looking at the optimal decision variable values associated with heating technologies, the diagrams show that ElB disappears from the optimal solutions already in the early stages of $\mathrm{CO}_{2}$ reduction. No significant increase of renewable electricity generation capacities above their lower bounds is registered within this range of emission reductions, after which a 100\% heating supply with HP represents the best trade-off for the heating sector. Only then the optimal solutions start to feature increasing renewable electricity generation capacities, widely following the same patterns as in the electricity only cases, until the point in which BioB in the heating sector becomes economically more convenient to further reduce emissions.

A higher share of BioB determines a drop of the electricity demand in the overall municipal energy system, which reduces electricity import and, in turn, mitigates related emissions $E m_{i m p}$. Thus, the transition from HP to BioB causes a significant interaction with the decision variables related to the electricity sector. The substitution of HP with BioB is so beneficial, both in terms of costs and in reducing electricity demand, that the capacities of the renewable electricity generation technologies decrease during the transition while $\mathrm{CO}_{2}$ emissions are reduced.

This transition from $\mathrm{HP}$ to BioB occurs at different levels of $\mathrm{CO}_{2}$ emissions reductions depending on the values of the economic parameters. For the same values of $p_{e l}$ and $p_{b i o}$, the transition is shifted toward lower emissions by a lower $d r$ as the difference in investment costs between the two technologies becomes less significant. On the other hand, for the same values of $d r$, the transition is shifted toward lower emissions by a higher $p_{e l}$ and/or a lower $p_{b i o}$ (biomass fuel costs are another term, relatively less significant, in $\left.C_{t o t}\right)$. Finally, the transition is more gradual for a higher $d r$.

Comparing the results of the integrated electricity and heating sectors (Figure 5) with those of the electricity sector only (Figure 3), it can be observed that the same emission reductions can be achieved with lower installed capacities of the renewable electricity generation technologies. In fact, the transition in the heating sector from the current technology mix to HP and, for higher emission reductions, to BioB reduces electricity demand and results in lower emissions because of less import from the grid. 

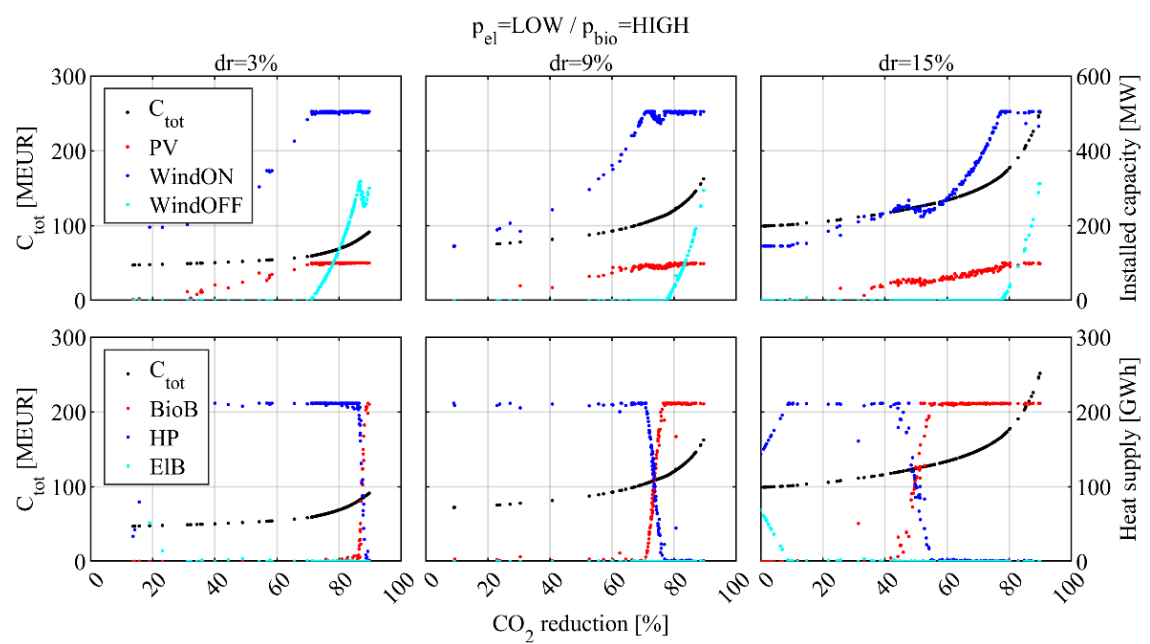

(a)

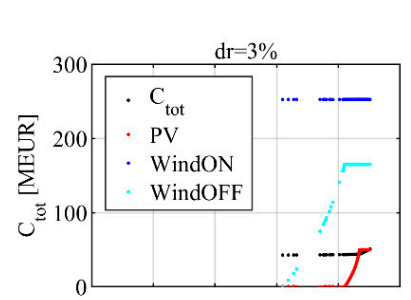

$\mathrm{p}_{\mathrm{el}}=\mathrm{MED} / \mathrm{p}_{\mathrm{bio}}=\mathrm{MED}$
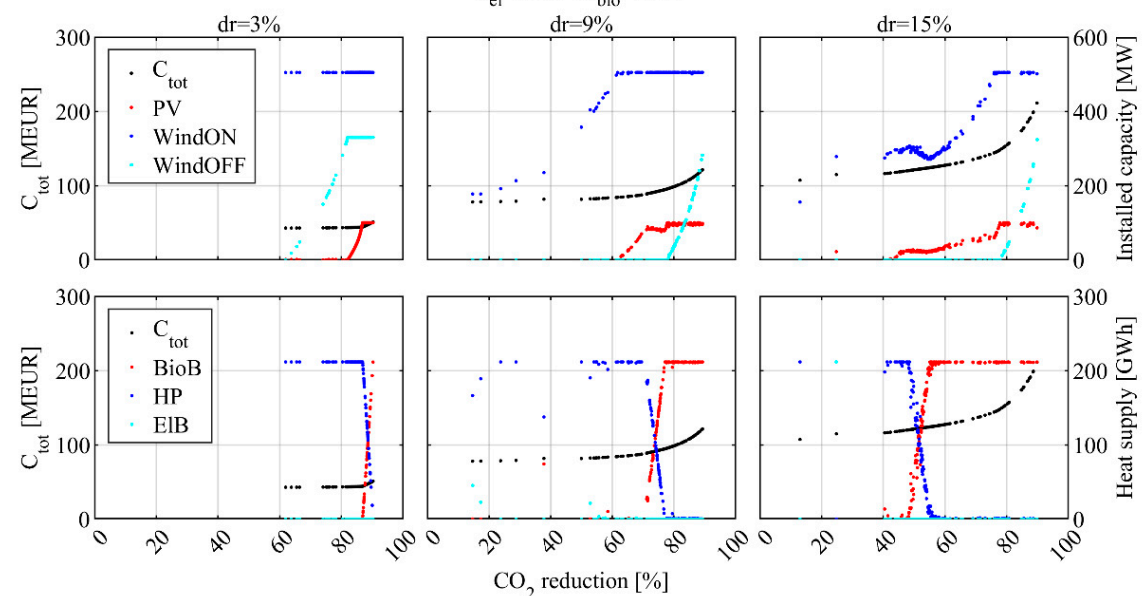

(b)

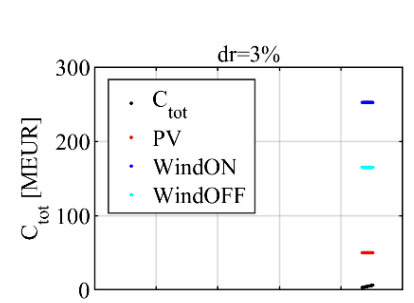

$\mathrm{p}_{\mathrm{el}}=\mathrm{HIGH} / \mathrm{p}_{\mathrm{bio}}=\mathrm{LOW}$
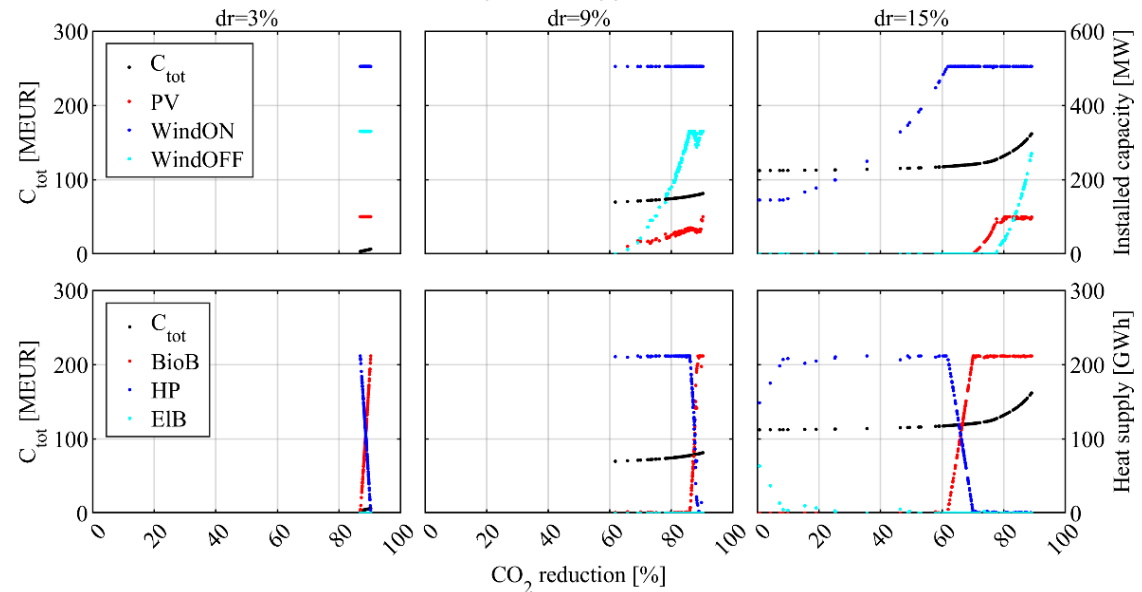

(c)

Figure 5. Electricity and heating sectors, on top: (a) for the combination $p_{e l}=\mathrm{LOW} / p_{b i o}=\mathrm{HIGH}$, in the middle: (b) with $p_{e l}=$ MED $p_{i o}=$ MED, bottom: (c) with $p_{e l}=\mathrm{HIGH} / p_{b i o}=\mathrm{LOW}$. Optimal results with all decision variables for the electricity sector in rows 1,3, and 5 (PV, WindON and WindOFF), decision variables for the heating sector in rows 2,4 , and 6 (BioB, HP, ElB), $C_{t o t}$ in all diagrams, nine cases in total for sensitivity analysis on $p_{e l} /$ pbio and $d r$. 
The trend of $P_{\text {el,maximp }}$ vs. $\mathrm{CO}_{2}$ emission reductions is shown in Figure 6. It can be interpreted as the composition of two effects: (i) as in the electricity only case $P_{\text {el,maximp }}$ decreases because of the growth of the installed capacities of PV, WindON and WindOFF; (ii) during the transitions from one heating technology to another $P_{\text {el,maximp }}$ follows the trend of the overall electricity demand, i.e., it is reduced when HP replaces ElB and then when BioB replaces HP. Minimum $P_{\text {el,maximp }}$ is $103 \mathrm{MW}$, with a 38\% reduction from the $165 \mathrm{MW}$ in Demand2020 scenario, and it is of course achieved with 100\% BioB supply of the individual heating sector and with maximum installed capacities of PV, WindON, and WindOFF.
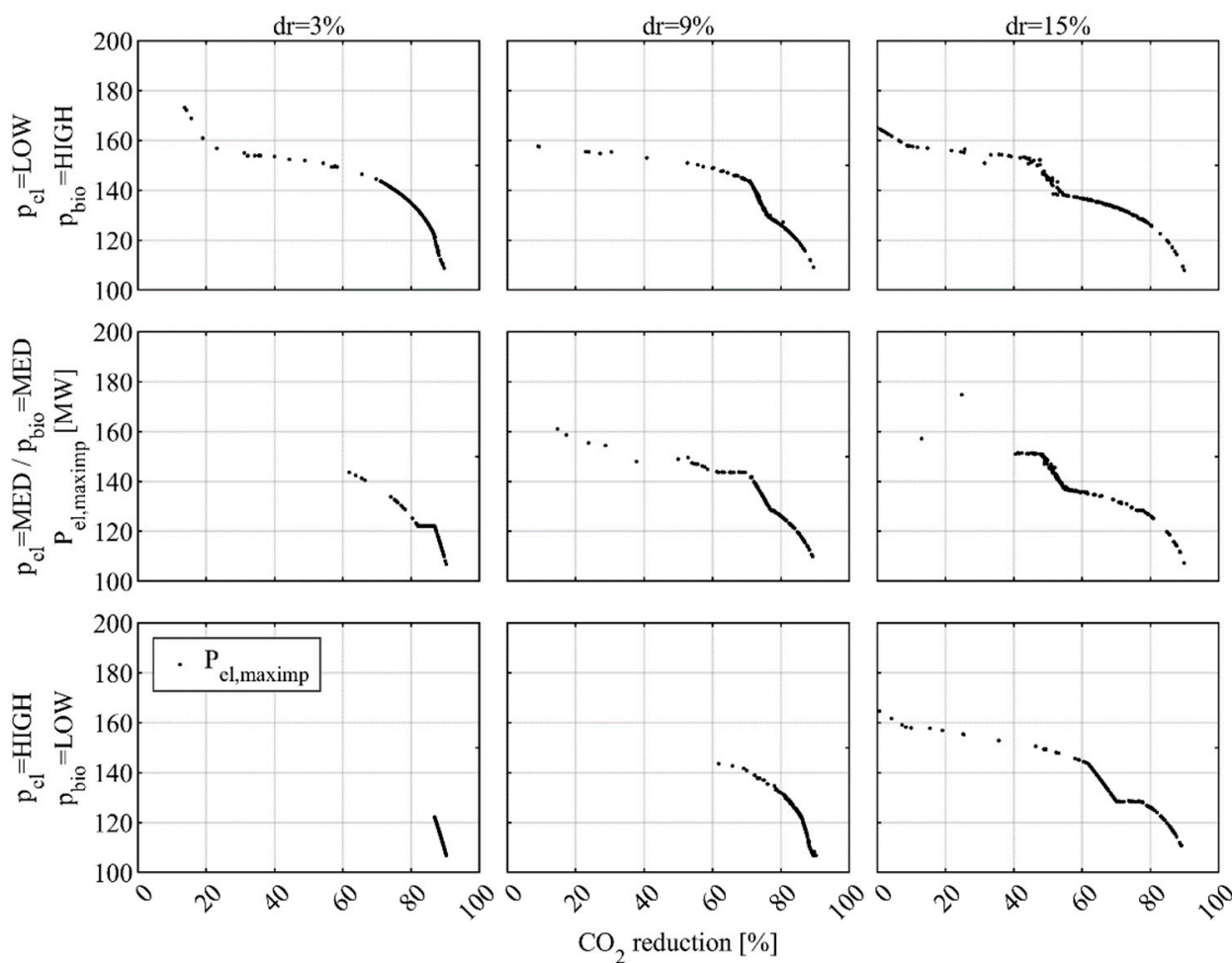

Figure 6. Electricity and heating sectors, $P_{e l, \text { maximp }}$ with all decision variables, sensitivity analysis for $p_{e l}$ and $d r$.

As a final note, the comparison in Figure 7 between the optimal $C_{\text {tot }}$ obtained with and without the individual heating sector shows that $C_{\text {tot }}$ is always lower, for the same level of $\mathrm{CO}_{2}$ emissions, when heating technologies are included in the set of decision variables. At $80 \%$ emission reductions, the costs are $1 \%, 7 \%$, and $16 \%$ lower for $d r=3 \%, 9 \%$, and $15 \%$ respectively. This underlines the importance of integrating and optimizing the electricity and heating sectors together, as these results are not trivial. 


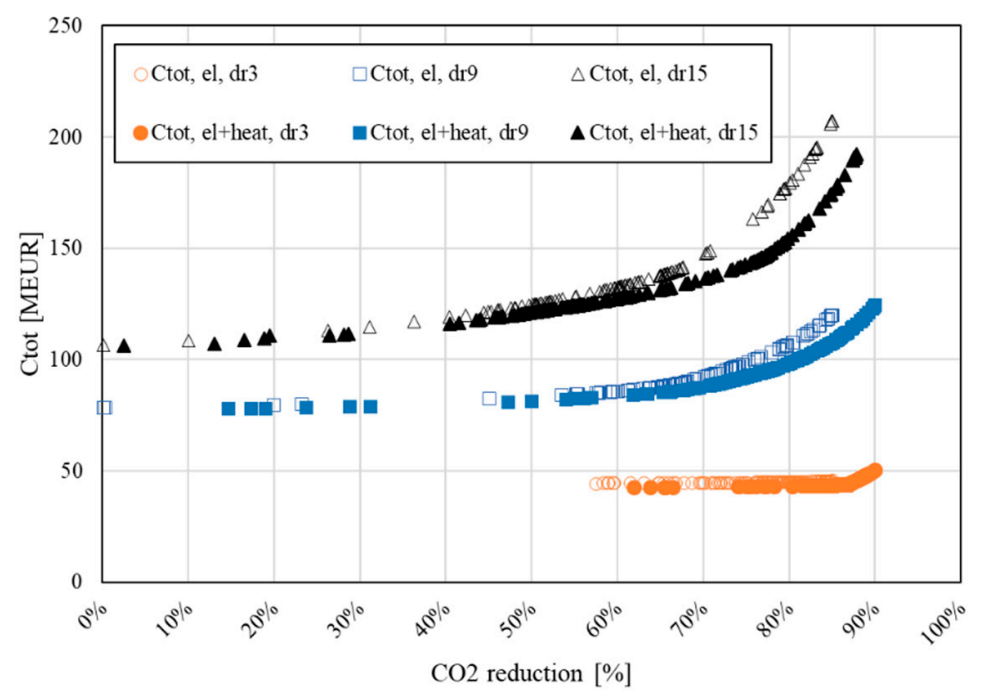

Figure 7. $C_{\text {tot }}$ compared for electricity only and integrated electricity and heating, $p_{e l}=40 \mathrm{EUR} / \mathrm{MWh}$, $p_{\text {bio }}=35 \mathrm{EUR} / \mathrm{MWh}$.

\subsection{Duration Curves for Electricity Import/Export}

The load on the supplying transmission line(s) is an important aspect to monitor in a municipal energy system. In this case study the connection with the national grid is modelled as a single transmission line with unlimited capacity. Figure 8 plots the duration curves of electricity import/export for the municipal energy system of Piteå according to the EnergyPLAN scenarios Demand2020 and Balanced 2020 and the optimized solutions at $60 \%$ and $80 \%$ emission reduction for the middle range values of $p_{e l}=40 \mathrm{EUR} / \mathrm{MWh}, p_{b i o}=35 \mathrm{EUR} / \mathrm{MWh}$, and $d r=9 \%$. The leftmost point of the duration curve for the power import/export is $P_{\text {el,maximp }}$ and rightmost one is $P_{\text {el,maxexp }}$ with a negative sign. Figure 9 presents the corresponding installed capacities of PV, WindON, and WindOFF.

The EnergyPLAN Demand2020 scenario was the starting point for the optimization cases (see Section 3), featuring installed WindON capacity is $145 \mathrm{MW} . P_{\text {el,maximp }}$ is $165 \mathrm{MW}$ and electricity import exceeds $100 \mathrm{MW}$ for about $400 \mathrm{~h}$, while $P_{\text {el,maxexp }}$ is $86 \mathrm{MW}$.

The EnergyPLAN Balanced2020 scenario achieves $42.5 \%$ emission reductions compared to Demand2020 by installing a total local electricity generation capacity of $305 \mathrm{MW}$, resulting, as intended, in an annually balanced import/export of electric energy. $P_{\text {el,maximp }}$ is $160 \mathrm{MW}$ and necessary import exceeds $100 \mathrm{MW}$ for about $200 \mathrm{~h}$. $P_{\text {el,maxexp }}$ is $204 \mathrm{MW}$ and export exceeds $100 \mathrm{MW}$ for about $400 \mathrm{~h}$.

The optimized solutions for the electricity sector only feature a total installed capacity of $523 \mathrm{MW}$ for $60 \%$ emission reductions and $776 \mathrm{MW}$ for $80 \%$ (the heating sector remains as in Demand2020 and Balanced2020). $P_{\text {el,maximp }}$ is $151 \mathrm{MW}$ (138 MW) for the $60 \%(80 \%)$ emission reduction case, with electricity import exceeding $100 \mathrm{MW}$ for about $100 \mathrm{~h}(45 \mathrm{~h}) . P_{\text {el,maxexp }}$ is $437 \mathrm{MW}(684 \mathrm{MW})$, with electricity export exceeding $100 \mathrm{MW}$ for about $3300 \mathrm{~h}(4700 \mathrm{~h})$, and $400 \mathrm{MW}$ for $20 \mathrm{~h}(1200 \mathrm{~h})$.

Optimizing the integrated electricity and heating sector results in total installed capacities of $479 \mathrm{MW}$ for $60 \%$ emission reductions and in $637 \mathrm{MW}$ for $80 \%$ (individual heating demand is completely supplied by heat pumps in the former case and by biomass boilers in the latter). $P_{\text {el,maximp }}$ is $151 \mathrm{MW}$ (149 MW) for the 60\% (80\%) emission reduction case, with electricity import exceeding $100 \mathrm{MW}$ for about $100 \mathrm{~h}(70 \mathrm{~h}) . P_{\text {el, maxexp }}$ is $413 \mathrm{MW}(514 \mathrm{MW})$, with electricity export exceeding $100 \mathrm{MW}$ for about $3100 \mathrm{~h}(3700 \mathrm{~h}), 400 \mathrm{MW}$ for $4 \mathrm{~h}(170 \mathrm{~h})$.

The decrease of $P_{\text {el,maximp }}$ is relatively small in the optimized cases, between $8.5 \%$ and $16.4 \%$ compared to the Demand2020 scenario. This is due to low wind speed during some cold winter days with high electricity demand, so that large installed capacities only have a minor impact on the import peak while having a major one on the export peak. Accordingly, only storage solutions can significantly lower $P_{\text {el,maximp }}$ without causing a disproportional increase of $P_{\text {el,maxexp }}$. In fact, a significant increase 
of $P_{\text {el,maxexp }}$ can be observed for all cases, from $135 \%$ to $500 \%$ compared to Demand 2020 scenario the higher are the installed capacities. The real capacity of transmission lines eventually pose a limitation to the expansion of such large-scale local electricity generation, which is technically possible in many of the Nordic municipalities as the technical wind potential is vast as is the available land area.

The differences in $P_{\text {el,maximp }}$ between the cases in which the individual heating sector is supplied by heat pumps ( $60 \%$ emission reduction) or by biomass boilers $(80 \%$ emission reduction) are limited as the two different electricity demands are paired with different amounts of installed capacities. It is worth noting, however, that the duration of high electricity import is significantly shortened compared to Demand2020 scenario, and that the integration between electricity and heating sector has a more limited effect on the growth of $P_{\text {el,maximp }}$.

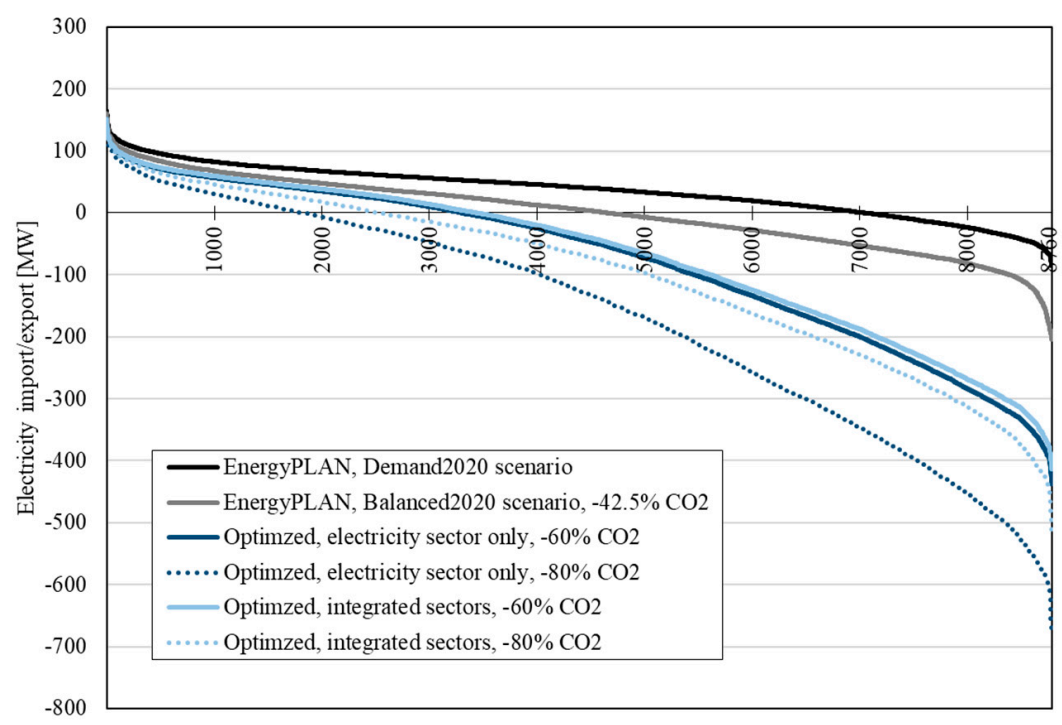

Figure 8. Duration curves for electricity import (positive)/export (negative) [MW].

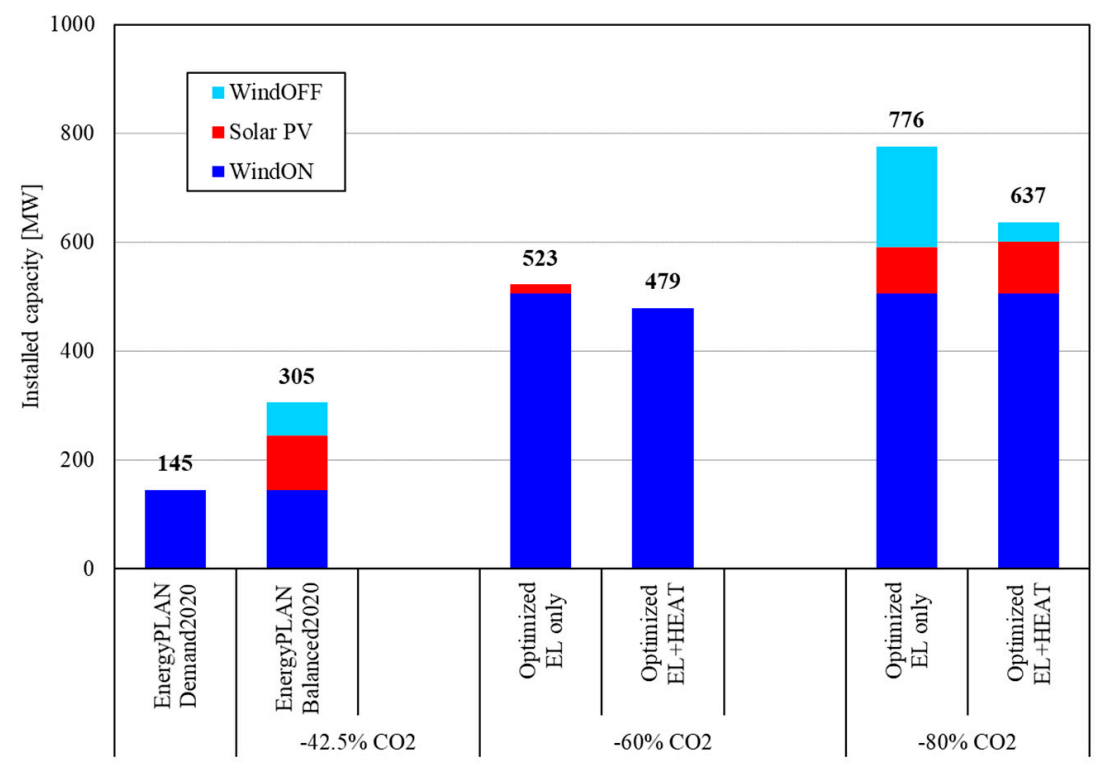

Figure 9. Installed capacities for selected scenarios and cases.

\subsection{Near-Zero Electricity Import/Export Balance Condition and $\mathrm{CO}_{2}$ Emissions}

Some solutions within the set of the optimal trade-offs are close to the near-zero electricity import/export balance condition, as discussed in the scenarios simulated with EnergyPLAN for Piteå 
(Section 3). Table 5 offers a comparison between the EnergyPLAN simulation results for Demand2020 and Balanced2020 scenarios and the optimal solutions closest to the near-zero balance condition from the results presented in Section 3 (with $p_{e l}=40 \mathrm{EUR} / \mathrm{MWh}, p_{b i o}=35 \mathrm{EUR} / \mathrm{MWh}$ and $d r=9 \%$ ). The renewable electricity generation technology used in these optimal solutions is WindON exclusively, with at most a small PV capacity. The optimal results obtained for integrated electricity and heating sectors at this near-zero balance condition provide a solution with the individual heating sector totally supplied by heat pumps. The comparison shows that optimal $C_{\text {tot }}$ values are $7.8 \%$ (electricity only) and $9.8 \%$ (integrated electricity and heating) lower than Balanced2020 scenario $C_{\text {tot }}$. Both optimized solutions provide emission reductions of about $36 \%$ with a cost increase of $4.6 \%$ (electricity only) or $2.5 \%$ (integrated electricity and heating) compared to Demand2020 scenario. The optimal solutions also result in lower $P_{\text {el,maximp }}$ compared to Demand2020 and Balanced2020 scenarios.

Table 5. Selected results approximating near-zero electricity import/export-balance.

\begin{tabular}{|c|c|c|c|c|c|}
\hline & Unit & $\begin{array}{l}\text { EnergyPLAN } \\
\text { Demand2020 }\end{array}$ & $\begin{array}{l}\text { EnergyPLAN } \\
\text { Balanced2020 }\end{array}$ & $\begin{array}{l}\text { Pareto Optimal Set } \\
\text { (Electricity Only) }\end{array}$ & $\begin{array}{c}\text { Pareto Optimal Set } \\
\text { (Electricity and Heating) }\end{array}$ \\
\hline Imp/Exp-balance & [GWh] & 0.3 & -6.5 & -60.6 & -1.55 \\
\hline Wind ON & [MW] & 145 & 145 & 288 & 253 \\
\hline Wind OFF & [MW] & 0 & 60 & 0 & 0 \\
\hline Heating (BioB|ElB|HP) & [GWh] & $50.4|60| 101.3$ & $50.4|60| 101.3$ & $50.4|60| 101.3$ & $0|0| 211.7$ \\
\hline$P_{\text {el,maximp }}$ & {$[\mathrm{MW}]$} & 165.4 & 160.0 & 158.7 & 152.7 \\
\hline
\end{tabular}

\section{Conclusions}

This paper exploited the benefits of combining EnergyPLAN, an energy system analysis and simulation tool, with a multi-objective evolutionary algorithm to investigate the optimal alternatives for the development of the integrated electricity and heating sectors of a municipal energy system in the Nordic context. Total annual costs and $\mathrm{CO}_{2}$ emissions were defined as objective functions to be minimized, sensitivity analyses on key economic parameters were performed and the impact on electricity import/export was also analyzed.

The results for the case study about Piteå (Norrbotten, Sweden), chosen as a representative municipality in the Nordic context, showed that $\mathrm{CO}_{2}$ emission reductions of at least $60 \%$ can be achieved without a considerable increase of total annual costs. Cost increases are always lower when electricity and heating sectors are integrated, since lower installed renewable electricity capacities are required to achieve given emission reductions. $\mathrm{CO}_{2}$ emission reductions higher than $60 \%$ can be achieved either by increased local renewable electricity generation or by replacing HP with BioB. After the introduction of biomass boilers, only larger renewable electricity generation capacities (usually WindOFF at this point, since WindON and solar PV, in spite of the low $12 \%$ capacity factor in the Nordic region, may have already reached their maximum installed capacities depending on the economic conditions) can further reduce emissions, with steeper cost increases. At $60 \%$ emission reductions, peak electricity import reduces by a maximum of $8 \%$, while peak electricity export increases by about $400 \%$, posing a challenge on the available transmission lines. At highest emission reductions peak electricity import $P_{\text {el,maximp }}$ can be reduced by up to $38 \%$.

The results obtained for Piteå municipality are of course case dependent. However, the conclusions can be extended to the entire Nordic region as the majority of the population is concentrated in municipalities similar to Piteå. By utilizing available potentials for WindON and solar PV, as well as by implementing a heat pump strategy for the heating demand not served by district heating, significant reductions of carbon emissions can be achieved without noteworthy increases of total annual energy system costs. For coastal areas, in economic conditions with high electricity prices and low discount rates, offshore wind capacities can feasibly contribute to emission reductions. A biomass heating 
strategy is indicated if reductions of peak electricity import are targeted, although the increase of peak electricity export related to the large expansion of local electricity generation also suggests the use of storage solutions.

The methodology of interfacing EnergyPLAN with a MOEA, together with an extensive sensitivity analysis on uncertain economic parameters, creates a wide set of optimal combinations of renewable electricity generation and heating options minimizing total annual costs and $\mathrm{CO}_{2}$ emission reductions. With this set of combinations, local decision-makers can now be made aware about the whole spectrum of optimal trade-off solutions and take more informed decisions for promoting a pathway toward a sustainable energy system for their municipality.

Future studies shall investigate the integration of electricity and heating sectors with different electricity storage options, including stationary and mobile storage, with peak electricity import/export and total annual system costs to be minimized. In the model of the heating sector, it would be important to consider district heating technology options such as large-scale heat pumps, solar thermal energy and thermal storage. Finally, analyzing impacts of policy developments, including $\mathrm{CO}_{2}$ targets, $\mathrm{CO}_{2}$ prices, and subsidies for technologies, and evaluating the potentials for local value and job creation are other areas for possible future work.

Author Contributions: R.F.: conceptualization; data curation; formal analysis; investigation; methodology; software; roles/writing—original draft. E.E.: supervision; validation; writing-review and editing. A.T.: formal analysis; methodology; software; supervision; validation; writing-review and editing. All authors have read and agreed to the published version of the manuscript.

Funding: This research was supported by the Interreg Nord funded project Arctic Energy-Low Carbon Self-Sufficient Community (ID: 20200589).

Conflicts of Interest: The authors declare no conflict of interest.

\section{Nomenclature}

$\begin{array}{ll}\text { BioB } & \text { Biomass boiler heating } \\ C_{a n n} & \text { Annualized capital cost } \\ C_{\text {tot }} & \text { Total annual system cost } \\ \text { CHP } & \text { Combined Heat and Power } \\ \text { CoM } & \text { EU Covenant of Mayors for Climate \& Energy } \\ \text { DH } & \text { District heating } \\ d r & \text { Discount rate } \\ E F_{\text {grid }} & \text { Grid emission factor } \\ \text { ElB } & \text { Electric boiler heating and direct electric heating } \\ \text { Em } m_{\text {imp }} & \text { CO } 2 \text { emissions of the electricity imported into the geographical scope of the model } \\ \text { Em } & \text { CO }{ }_{\text {sys }} \text { emissions of the modelled integrated energy system (electricity and heating) } \\ \text { EU } & \text { European Union } \\ \text { GHG } & \text { Greenhouse gas } \\ \text { HP } & \text { Heat-pump } \\ \text { IPCC } & \text { Intergovernmental Panel on Climate Change } \\ \text { JRC } & \text { European Joint Research Center } \\ \text { LCA } & \text { Life Cycle Assessment } \\ \text { LCOE } & \text { Levelized cost of electricity } \\ \text { MEUR } & \text { Millions of euros (equivalent to M€) } \\ \text { MOEA } & \text { Multi-objective evolutionary algorithm } \\ \text { MOOP } & \text { Multi-objective optimization problem } \\ \text { NEEFE } & \text { National and European Emission Factors for Electricity consumption } \\ \text { O\&M } & \text { Operation and maintenance } \\ & \end{array}$




$\begin{array}{ll}p_{b i o} & \text { Biomass price } \\ p_{e l} & \text { Electricity price } \\ P_{\text {el,maxexp }} & \text { Annual peak (maximum) electricity export from the geographical scope of the model } \\ P_{\text {el,maximp }} & \text { Annual peak (maximum) electricity import from the geographical scope of the model } \\ \text { PV } & \text { Photovoltaic; also in this paper: utility scale solar photovoltaic systems } \\ \text { SEAP } & \text { Sustainable Energy Action Plan } \\ \text { TIMES } & \text { The Integrated MARKAL-EFOM System } \\ \text { UNFCCC } & \text { United Nations Framework Convention on Climate Change } \\ \text { WindON } & \text { Onshore windpower } \\ \text { WindOFF } & \text { Offshore windpower }\end{array}$

\section{References}

1. European Council. 2030 Climate and Energy Policy Framework; European Council: Brussels, Belgium, 2014.

2. European Parliament. REGULATION (EU) 2018/842 on Binding Greenhouse Gas Emission Reductions by Member States from 2021 to 2030; European Parliament: Brussels, Belgium, 2018.

3. IEA. Global Energy and CO2 Status Report 2018; International Energy Agency: Paris, France, 2019.

4. EPA. Sweden Sveriges Officiella Statistik-Nationella Utsläpp och Upptag av Växthusgaser. Available online: https://www.naturvardsverket.se/Sa-mar-miljon/Statistik-A-O/Vaxthusgaser-territoriellautslapp-och-upptag/ (accessed on 10 May 2019).

5. Micropolis Arctic Energy_Energiaomavarainen Pohjoinen-Greenpolis. Available online: https://www. greenpolis.fi/en/projektit/arctic-energy/ (accessed on 16 May 2019).

6. Hirvonen, J.; ur Rehman, H.; Sirén, K. Techno-economic optimization and analysis of a high latitude solar district heating system with seasonal storage, considering different community sizes. Sol. Energy 2018, 162, 472-488. [CrossRef]

7. Lund, H.; Werner, S.; Wiltshire, R.; Svendsen, S.; Thorsen, J.E.; Hvelplund, F.; Mathiesen, B.V. 4th Generation District Heating (4GDH). Integrating smart thermal grids into future sustainable energy systems. Energy 2014, 68, 1-11. [CrossRef]

8. Paiho, S.; Reda, F. Towards next generation district heating in Finland. Renew. Sustain. Energy Rev. 2016, 65, 915-924. [CrossRef]

9. Werner, S. International review of district heating and cooling. Energy 2017, 137, 617-631. [CrossRef]

10. Averfalk, H.; Ingvarsson, P.; Persson, U.; Gong, M.; Werner, S. Large heat pumps in Swedish district heating systems. Renew. Sustain. Energy Rev. 2017, 79, 1275-1284. [CrossRef]

11. Hast, A.; Rinne, S.; Syri, S.; Kiviluoma, J. The role of heat storages in facilitating the adaptation of district heating systems to large amount of variable renewable electricity. Energy 2017, 137, 775-788. [CrossRef]

12. Levihn, F. CHP and heat pumps to balance renewable power production: Lessons from the district heating network in Stockholm. Energy 2017, 137, 670-678. [CrossRef]

13. Schweiger, G.; Rantzer, J.; Ericsson, K.; Lauenburg, P. The potential of power-to-heat in Swedish district heating systems. Energy 2017, 137, 661-669. [CrossRef]

14. Jordehi, A.R. Optimisation of demand response in electric power systems, a review. Renew. Sustain. Energy Rev. 2019, 103, 308-319. [CrossRef]

15. Avelin, A.; Dahlquist, E.; Wallin, F. Effect of different renovation actions, their investment cost and future potential. Energy Procedia 2017, 143, 73-79. [CrossRef]

16. Broberg, T.; Persson, L. Is our everyday comfort for sale? Preferences for demand management on the electricity market. Energy Econ. 2016, 54, 24-32. [CrossRef]

17. Hellmer, S. Switching Costs, Switching Benefits and Lock-In Effects-The Reregulated Swedish Heat Market. Energy Environ. 2010, 21, 563-575. [CrossRef]

18. Wöhler, M.; Andersen, J.S.; Becker, G.; Persson, H.; Reichert, G.; Schön, C.; Schmidl, C.; Jaeger, D.; Pelz, S.K. Investigation of real life operation of biomass room heating appliances-Results of a European survey. Appl. Energy 2016, 169, 240-249. [CrossRef]

19. NO OED. Energy Use by Sector. Available online: https://energifaktanorge.no/en/norsk-energibruk/ energibruken-i-ulike-sektorer/ (accessed on 10 May 2019). 
20. Finnish Energy Finnish Energy-District Heating and Cooling. Available online: https://energia.fi/ en/news_and_publications/statistics/district_heating_statistics/district_heating_and_cooling (accessed on 10 May 2019).

21. Swedish Energy Agency. Energiläget i Siffror 2019. Available online: http://www.energimyndigheten.se/ nyhetsarkiv/2019/Nu-finns-siffror-pa-energilaget-i-Sverige/ (accessed on 10 May 2019).

22. NORDPOOL. Historical Market Data. Available online: https://www.nordpoolgroup.com/historical-marketdata/ (accessed on 13 May 2019).

23. Energiföretagen. "Samling för nätkapacitet" samlade stort nätverk-Energiföretagen Sverige. Available online: https:/www.energiforetagen.se/medlemsnyheter/2019/april/samling-for-natkapacitetsamlade-stort-natverk/ (accessed on 17 October 2019).

24. Svenska kraftnät. Både Kort- och Långsiktiga Lösningar Behövs för att Möta Kapacitetsbristen. Available online: https://www.svk.se/om-oss/nyheter/allmanna-nyheter/2018/bade-kort--och-langsiktigalosningar-behovs-for-att-mota-kapacitetsbristen/ (accessed on 13 May 2019).

25. Gustafsson, M.S.; Myhren, J.A.; Dotzauer, E. Mapping of Heat and Electricity Consumption in a Medium Size Municipality in Sweden. Energy Procedia 2017, 105, 1434-1439. [CrossRef]

26. Alarcon-Rodriguez, A.; Ault, G.; Galloway, S. Multi-objective planning of distributed energy resources: A review of the state-of-the-art. Renew. Sustain. Energy Rev. 2010, 14, 1353-1366. [CrossRef]

27. Baños, R.; Manzano-Agugliaro, F.; Montoya, F.G.; Gil, C.; Alcayde, A.; Gómez, J. Optimization methods applied to renewable and sustainable energy: A review. Renew. Sustain. Energy Rev. 2011, 15, 1753-1766. [CrossRef]

28. McKenna, R.; Bertsch, V.; Mainzer, K.; Fichtner, W. Combining local preferences with multi-criteria decision analysis and linear optimization to develop feasible energy concepts in small communities. Eur. J. Oper. Res. 2018, 268, 1092-1110. [CrossRef]

29. Lez-Briones, A.G.; De La Prieta, F.; Mohamad, M.S.; Omatu, S.; Corchado, J.M. Multi-agent systems applications in energy optimization problems: A state-of-the-art review. Energies 2018, 11, 1928. [CrossRef]

30. Mendes, G.; Ioakimidis, C.; Ferrão, P. On the planning and analysis of Integrated Community Energy Systems: A review and survey of available tools. Renew. Sustain. Energy Rev. 2011, 15, 4836-4854. [CrossRef]

31. Lyden, A.; Pepper, R.; Tuohy, P.G. A modelling tool selection process for planning of community scale energy systems including storage and demand side management. Sustain. Cities Soc. 2018, 39, 674-688. [CrossRef]

32. Ringkjøb, H.K.; Haugan, P.M.; Solbrekke, I.M. A review of modelling tools for energy and electricity systems with large shares of variable renewables. Renew. Sustain. Energy Rev. 2018, 96, 440-459. [CrossRef]

33. Scheller, F.; Bruckner, T. Energy system optimization at the municipal level: An analysis of modeling approaches and challenges. Renew. Sustain. Energy Rev. 2019, 105, 444-461. [CrossRef]

34. Aalborg University. EnergyPLAN|Advanced Energy Systems Analysis Computer Model. Available online: https://www.energyplan.eu/ (accessed on 13 May 2019).

35. Østergaard, P.A. Wind power integration in Aalborg Municipality using compression heat pumps and geothermal absorption heat pumps. Energy 2013, 49, 502-508. [CrossRef]

36. Wänn, A.; Connolly, D.; Gallachóir, B.Ó. Investigating 100\% renewable energy supply at regional level using scenario analysis. Int. J. Sustain. Energy Plan. Manag. 2014, 3, 21-32.

37. Østergaard, P.A. Reviewing EnergyPLAN simulations and performance indicator applications in EnergyPLAN simulations. Appl. Energy 2015, 154, 921-933. [CrossRef]

38. Novosel, T.; Pukšec, T.; Krajačić, G.; Duić, N. Role of District Heating in Systems with a High Share of Renewables: Case Study for the City of Osijek. Energy Procedia 2016, 95, 337-343. [CrossRef]

39. Bačeković, I.; Østergaard, P.A. A smart energy system approach vs. a non-integrated renewable energy system approach to designing a future energy system in Zagreb. Energy 2018, 155, 824-837. [CrossRef]

40. Cabrera, P.; Lund, H.; Carta, J.A. Smart renewable energy penetration strategies on islands: The case of Gran Canaria. Energy 2018, 162, 421-443. [CrossRef]

41. Child, M.; Nordling, A.; Breyer, C. Scenarios for a sustainable energy system in the Åland Islands in 2030. Energy Convers. Manag. 2017, 137, 49-60. [CrossRef]

42. Batas Bjelić, I.; Rajaković, N. Simulation-based optimization of sustainable national energy systems. Energy 2015, 91, 1087-1098. [CrossRef] 
43. Mahbub, M.S.; Cozzini, M.; Østergaard, P.A.; Alberti, F. Combining multi-objective evolutionary algorithms and descriptive analytical modelling in energy scenario design. Appl. Energy 2016, 164, 140-151. [CrossRef]

44. Prina, M.G.; Cozzini, M.; Garegnani, G.; Manzolini, G.; Moser, D.; Filippi Oberegger, U.; Pernetti, R.; Vaccaro, R.; Sparber, W. Multi-objective optimization algorithm coupled to EnergyPLAN software: The EPLANopt model. Energy 2018, 149, 213-221. [CrossRef]

45. Thellufsen, J.Z.; Nielsen, S.; Lund, H. Implementing cleaner heating solutions towards a future low-carbon scenario in Ireland. J. Clean. Prod. 2019, 214, 377-388. [CrossRef]

46. Toffolo, A.; Benini, E. Genetic diversity as an objective in multi-objective evolutionary algorithms. Evol. Comput. 2003, 11, 151-167. [CrossRef] [PubMed]

47. Vesterlund, M.; Toffolo, A. Design Optimization of a District Heating Network Expansion, a Case Study for the Town of Kiruna. Appl. Sci. 2017, 7, 488. [CrossRef]

48. Connolly, D.; Lund, H.; Mathiesen, B.V.; Leahy, M. A review of computer tools for analysing the integration of renewable energy into various energy systems. Appl. Energy 2010, 87, 1059-1082. [CrossRef]

49. Goel, T.; Stander, N. A non-dominance-based online stopping criterion for multi-objective evolutionary algorithms. Int. J. Numer. Methods Eng. 2010, 84, 661-684. [CrossRef]

50. Pelletsförbundet Statistik|Pelletsförbundet. Available online: http://pelletsforbundet.se/statistik/ (accessed on 14 May 2019).

51. Steinbach, J.; Staniaszek, D. Discount Rates in Energy System Analysis. Discussion Paper; Fraunhofer ISI, Buildings Performance Institute Europe (BPIE): Karlsruhe, Germany, 2015.

52. García-Gusano, D.; Espegren, K.; Lind, A.; Kirkengen, M. The role of the discount rates in energy systems optimisation models. Renew. Sustain. Energy Rev. 2016, 59, 56-72. [CrossRef]

53. Danish Energy Agency. Energinet Technology Data. Available online: https://ens.dk/en/our-services/ projections-and-models/technology-data (accessed on 14 May 2019).

54. Tsiropoulos, I.; Tarvydas, D.; Zucker, A. Cost Development of Low Carbon Energy Technologies; Joint Research Centre (JRC), European Commission: Brussels, Belgium, 2018.

55. Moles, C.; Sigfusson, B.; Spisto, A.; Vallei, M.; Weidner, E.; Giuntoli, J.; Jäger-Waldau, A.; Lacal Arántegui, R.; Lazarou, S.; Magagna, D.; et al. Energy Technology Reference Indicator (ETRI) Projections for 2010-2050; EU Publications: Luxembourg, 2014.

56. Koffi, B.; Cerutti, A.K.; Duerr, M.; Iancu, A.; Kona, A.; Janssens-Maenhout, G. Covenant of Mayors for Climate and Energy: Default Emission Factors for Local Emission Inventories-Version; EUR 28718 EN; Publications Office of the European Union: Luxembourg, 2017.

57. Moro, A.; Lonza, L. Electricity carbon intensity in European Member States: Impacts on GHG emissions of electric vehicles. Transp. Res. Part D Transp. Environ. 2018, 64, 5-14. [CrossRef]

58. Porsö, C. Rapportering av Energianvändningen och Växthusgasutsläppen 2017; Stockholms stad: Stockholm, Sweden, 2017.

59. Wikman, Å. Klimat-och Energiplan Piteå; Piteå Kommun: Piteå, Sweden, 2010.

60. Piteå Kommun. Sammanträdesprotokoll; Piteå Kommun: Piteå, Sweden, 2017.

61. Piteå Kommun. Lägesrapport Uppföljning av Klimat-och Energiplanens Mål; Piteå Kommun: Piteå, Sweden, 2015.

62. SCB. Statistikdatabasen. Available online: http://www.statistikdatabasen.scb.se/ (accessed on 15 May 2019).

63. Statisticon AB. Befolkningsprognos 2018-2030 Piteå Kommun; Statisticon AB: Uppsala, Sweden, 2018.

64. Energikontor. Norr Energiluppen. Available online: http://www.energiluppen.se/ (accessed on 15 May 2019).

65. Piteå Kommun. Piteå Climate and Energy Plan 2010; Supporting Documents; Piteå Kommun: Piteå, Sweden, 2016.

66. Piteå Industries. Energy Data of Local Industries in Piteå; Piteå Industries: Piteå, Sweden, 2016; (received by email from industrial representatives in May 2017).

67. PiteEnergi AB. Årsredovisning och Koncernredovisning för AB PiteEnergi, Räkenskapsåret 2015; PiteEnergi AB: Piteå, Sweden, 2016.

68. Swedish Energy Agency. Ny Samlingspublikation: Energistatistik för Småhus, Flerbostadshus och Lokaler 2013. Available online: http://www.energimyndigheten.se/nyhetsarkiv/2014/ny-samlingspublikationenergistatistik-for-smahus-flerbostadshus-och-lokaler-2013/ (accessed on 15 May 2019).

69. Swedish Energy Agency. Bostäder och Lokaler. Available online: http://www.energimyndigheten.se/statistik/ bostader-och-lokaler/ (accessed on 15 May 2019).

70. Miljö- och Energidepartementet. Miljöbalk (1998:808); Sveriges Riksdag: Stockholm, Sweden, 1999. 
71. Svenska kyl och Värmepumpföreningen. Värmepumpsförsäljning. Available online: https://skvp.se/aktuellto-opinion/statistik/varmepumpsforsaljning (accessed on 15 May 2019).

72. Piteå Kommun Vindbruksplan-Översiktsplan. Available online: https://www.pitea.se/Invanare/Boendemiljo/Planer-och-fysisk-planering/oversiktsplan-2030/Vindbruksplan/ (accessed on 15 May 2019).

73. Sveriges Radio; P4 Norrbotten. Storsatsning på vindkraft i Piteå skärgård. Available online: https: //sverigesradio.se/sida/artikel.aspx?programid=98\&artikel=1022396 (accessed on 15 May 2019).

74. Svenska Kraftnät. Integrering av Vindkraft; Svenska Kraftnät: Sundbyberg, Sweden, 2013.

(C) 2020 by the authors. Licensee MDPI, Basel, Switzerland. This article is an open access article distributed under the terms and conditions of the Creative Commons Attribution (CC BY) license (http://creativecommons.org/licenses/by/4.0/). 